University of Rhode Island

DigitalCommons@URI

Open Access Master's Theses

1992

\title{
Tourism Management in the Galapagos Islands: A Social Carrying Capacity Study
}

Claudia Anne Reinhart

University of Rhode Island

Follow this and additional works at: https://digitalcommons.uri.edu/theses

\section{Recommended Citation}

Reinhart, Claudia Anne, "Tourism Management in the Galapagos Islands: A Social Carrying Capacity Study" (1992). Open Access Master's Theses. Paper 1821.

https://digitalcommons.uri.edu/theses/1821

This Thesis is brought to you for free and open access by DigitalCommons@URI. It has been accepted for inclusion in Open Access Master's Theses by an authorized administrator of DigitalCommons@URI. For more information, please contact digitalcommons-group@uri.edu. 
TOURISM MANAGEMENT IN THE GALAPAGOS ISLANDS:

A SOCIAL CARRYING CAPACITY STUDY

BY

CLAUDIA ANNE REINHART

A THESIS SUBMITTED IN PARTIAL FULFILLMENT OF THE REQUIREMENTS FOR THE DEGREE OF

MASTER OF ARTS

IN

MARINE AFFAIRS

$27 ? \div 2 \%$

UNIVERSITY OF RHODE ISLAND

1992 


\section{ABSTRACT}

Social carrying capacity is crucial to the long term survival of a tourist destination. The purpose of this thesis is to help tourism managers in the Galápagos Islands understand the critical factors related to social carrying capacity in order to maximize the value of the resource. It includes: a literature review of social carrying capacity studies, a description of the Galápagos Islands, tourism, and a description of visitors and their levels of satisfaction based on two surveys.

Visitors to the Galápagos Islands are all very different, and the results of the surveys demonstrate the wide range of visitors. As was expected, the results show that as number of groups encountered increases, willingness to pay decreases although the correlation was low. Social carrying capacity is a very dynamic concept and cannot be accurately measured in the Galápagos. Attempts to measure social impacts based on use levels and satisfaction should not be made. The Park service should continue monitoring use levels at the individual sites and make the necessary adjustments when problems occur. 


\section{ACKNOWLEDGEMENTS}

I would like to thank my major professor, Dr. Richard pollnac, without his encouragement I would still be searching for a topic. Special thanks goes to Bruce Epler for all his help providing the data and encouraging CRC to fund part of my trip to the Galápagos. Thanks to stephen F. Edwards for allowing me to use some of his data. I would also like to thank my committee members Dr. Timothy Tyrrell and Dr. Gerald Krausse, for all their help while Dr. Pollnac was away.

A big thank you goes to my mother and sister. I could not have finished without their help. And thank you to all my friends who supported me throughout this endeavor. 
ABSTRACT...............................

ACKNOWLEDGEMENTS..............................

TABLE of CONTENTS............................

LIST OF TABLES.................................

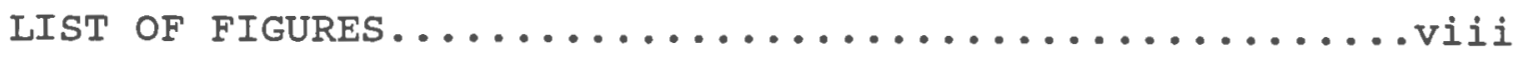

\section{CHAPTER}

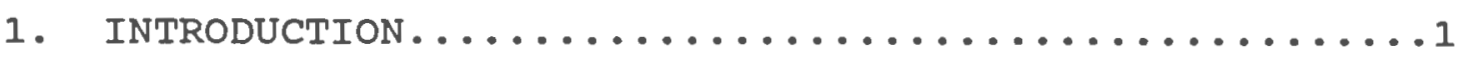

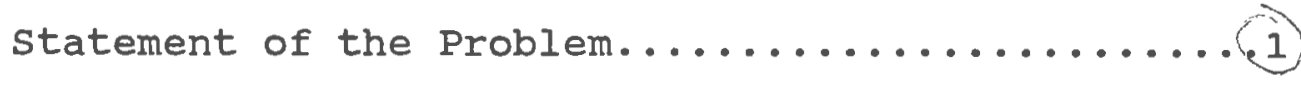
objective of the study...................

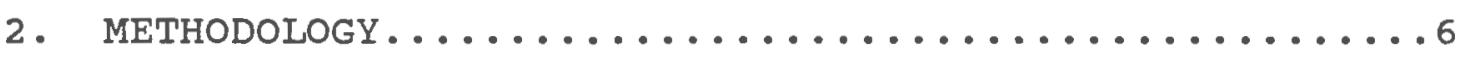

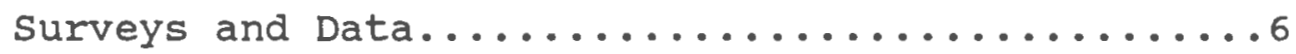

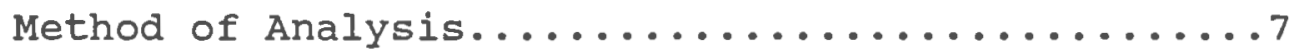

Limitations........................

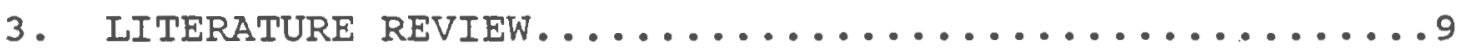

The Concept of Carrying Capacity.............9

Problems with Carrying Capacity.............12

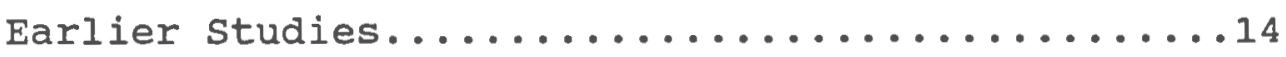

summary.............................

4. THE GALAPAgOS ISIANDS AND TOURISM............ 18

History ............................

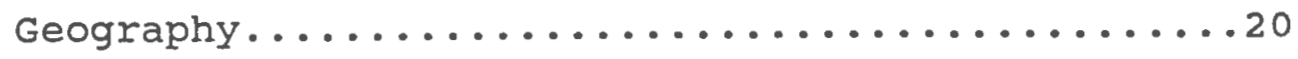

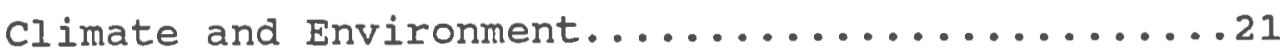




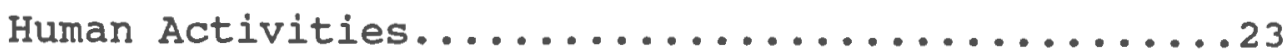

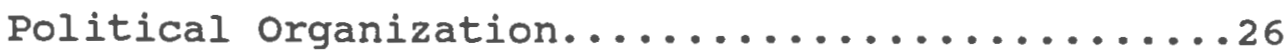

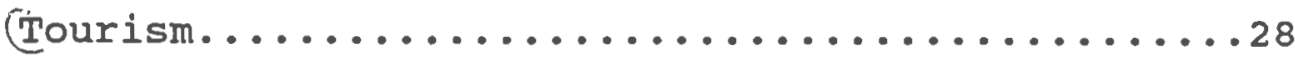

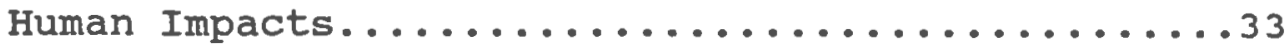

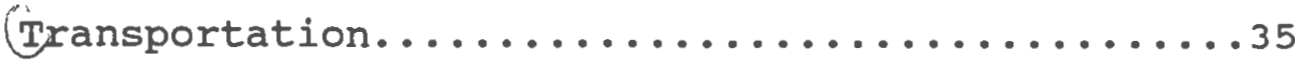

Conflicts with Tourism. .................

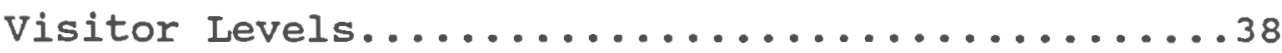

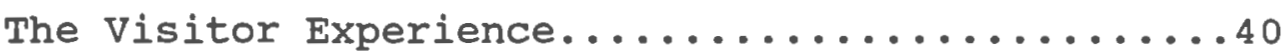

Estimates of Carrying Capacity............42

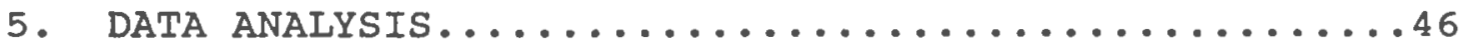

Introduction........................

Duration of visits.......................

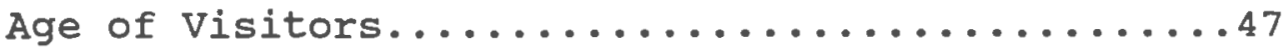

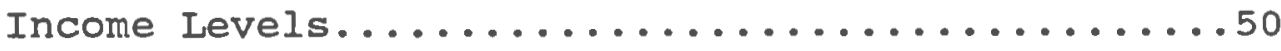

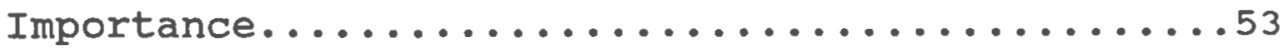

Accomodations........................... 44

Places of origin........................

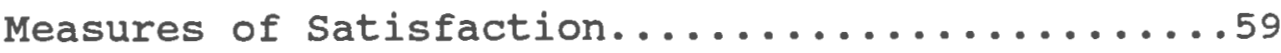

Use Levels and Satisfaction..............62

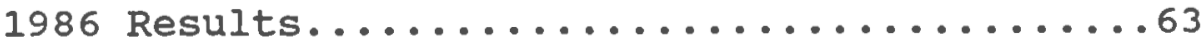

1991 Results.....................68

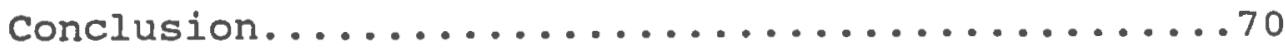

6. DISCUSSION..........................

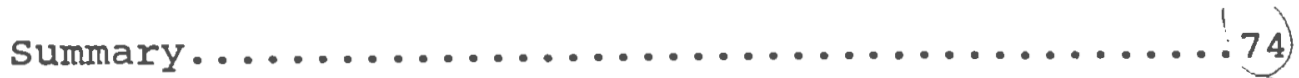

Recommendations................... 
APPENDIX

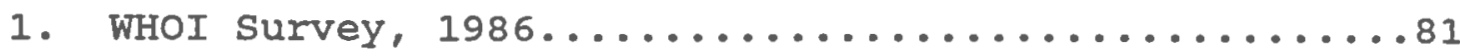

2. CRC survey, 1991...........................

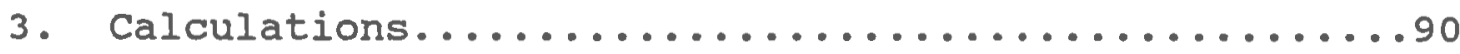

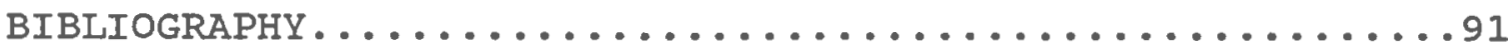




\section{LIST OF TABLES}

Table

Page

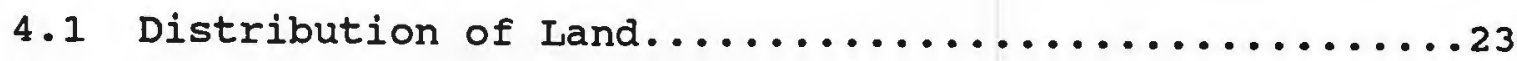

4.2 Distribution of Human Populations, $1982 \ldots \ldots \ldots . . . .24$

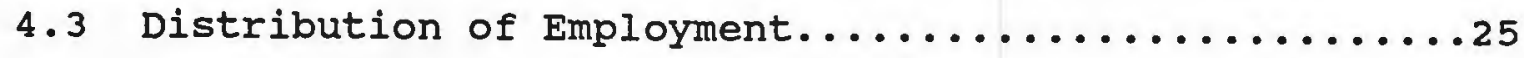

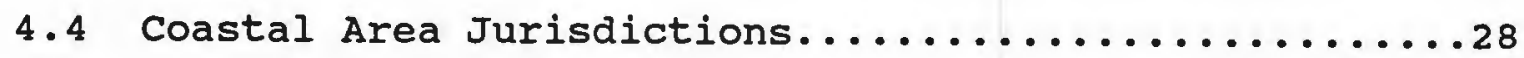

4.5 Number of Visitors at selected sites.................

4.6 National and Foreign Visitors to PNG, 1974-1987....38

4.7 Physical Carrying Capacities...................43

4.8 Effective Carrying Capacities...................44

5.1 Frequency Distribution, Age $1986 \ldots \ldots \ldots \ldots \ldots \ldots$

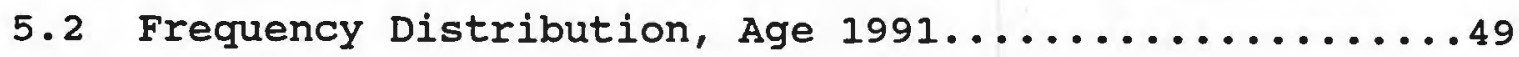

5.3 Frequency Distibution, Income 1986.................

5.4 Frequency Distribution, Income 1991.............52

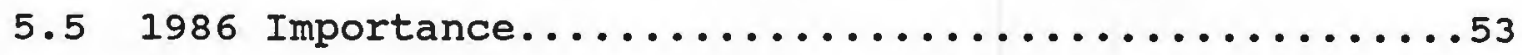

5.6 Average Number of National and International Visitors

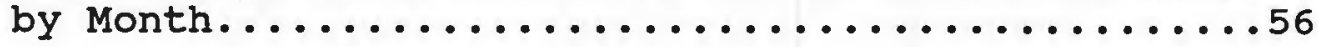

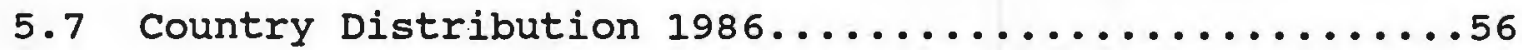

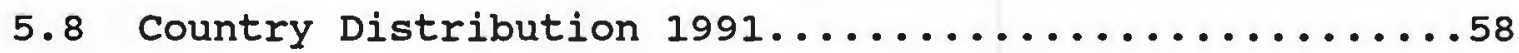

5.91986 summary of satisfaction.................60

5.101991 summary of satisfaction.................61

5.11 willingness to Pay..........................64

5.12 Willingness to Pay by Number of Groups............64

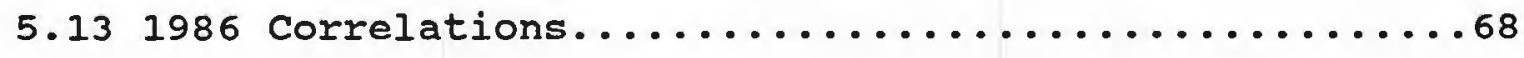

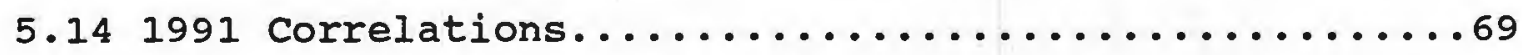




\section{LIST OF FIGURES}

Figure

Page

4.1 Map of the Galápagos Archipelago................21

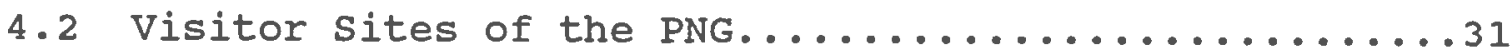

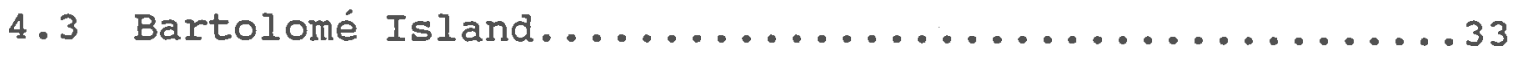

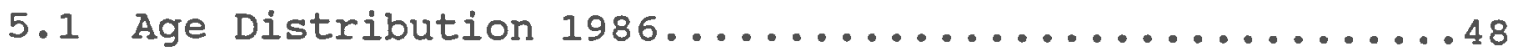

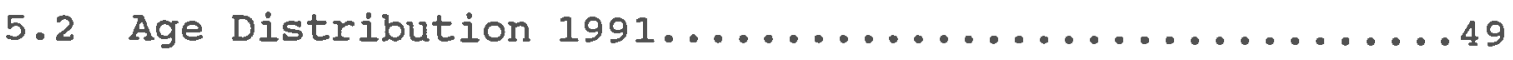

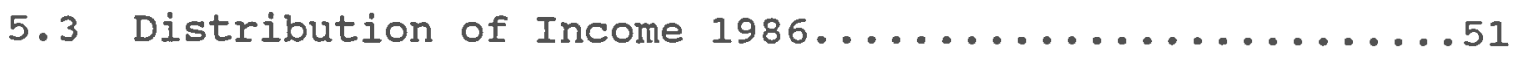

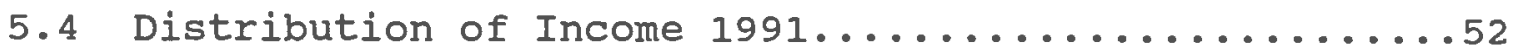

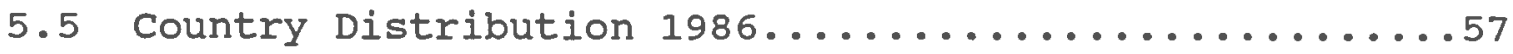

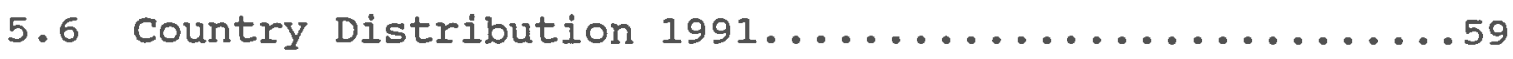

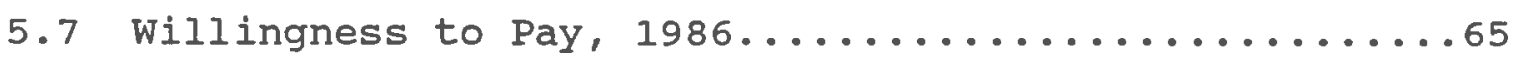

5.8 Average Response to Number of Groups Encountered.....72 
CHAPTER 1

INTRODUCTION

\section{Statement of the Problem}

The Galápagos Islands, Ecuador, are a popular

destination for visitors from all over the world. The unique ecology of the islands attracts people who come to see rare species in their natural habitats. This growing form of tourism, known as ecotourism, poses a threat to the beauty of these islands, which is the basis on which this tourism rests. Proper management aimed at minimizing human impacts is a necessity for the survival of both the ecotourism industry and the ecological integrity of the area. The proposed research is aimed at providing a subset of the information necessary for rational management of this important resource.

The Galápagos Islands National Park was established in 1959 and takes up 97 percent of the islands' land mass. Many tourists visit by cruise ship. They fly from Quito or Guayaquil, Ecuador, to the Islands, where most board ships immediately, and the rest stay in hotels. In the last ten years, there has been an increase in land-based tourism in which visitors stay in hotels, taking day trips of various lengths on small boats to points of interest. The growing land-based tourism industry has attracted more mainland Ecuador nationals seeking work. As a result, the resident population is increasing as well.

Tourism is a fast growing industry around the world; it 
serves as a tool for economic development in areas where other resources for economic advancement are scarce. The results of haphazard growth in tourism include damage to the environment, as well as negative socio-economic impacts on local populations. Dependence on a single sector such as tourism leaves the local economy a victim to fluctuations in the world economy. Management designed to minimize the negative impacts of tourism is very difficult in the Galápagos. Currently, environmental impacts due to seemingly uncontrolled growth in the number of visitors and residents are a major concern.

Tourism in the Galápagos Islands has increased rapidly over the last twenty years as the number of visitors rose from approximately 4,600 in 1971 to 42,000 in 1989 (Epler, 1990). Accurate information is rarely available, and it is often conflicting and inconsistent. Management strategies must be based on accurate data on the quantity and activity of visitors. The true status of the tourism industry in the Galápagos Islands cannot be determined in the absence of accurate visitor information. A quota on the number of visitors was set at 12,000 per year in 1973, but this quota actually represented a maximum capacity based on the installed operations at one particular time. The government considered all the boats and hotels and calculated how many visitor days were possible if every boat and hotel were filled to capacity every day of the year (Craig McFarland, telephone interview by author, Jan 17, 1992). Assumptions were made based on a certain length of stay by each visitor. 
This "quota" of 12,000 visitors per year was reached in 1979. A high level commission increased this "quota" to 25,000 in 1981 (Epler, 1990). The "quota" does not represent an effort by management to limit the number of visitors, and therefore it does not address the issue of resource protection in the Islands.

The term "carrying capacity" is often used in tourism management when referring to visitor quotas; but its meaning is unclear, making its application difficult. It is often thought to be a single value that determines the limits on the use of an area for recreational use or animal populations, but it is actually a range of levels established by management depending on their objectives. There are four types of carrying capacity identified by Shelby and Heberlein (1986), ecological, physical, facility, and social which is the focus of this study. Social carrying capacity is concerned with social impacts such as the number of people encountered at each attraction site and its effect on satisfaction.

social carrying capacity is difficult to establish, but it may be a very useful management tool. According to Shelby and Heberlein, the criteria for determining social impacts are: visitor satisfaction, perceived crowding, and contact preference standards, which focuses on impacts in terms of encounters with other parties (1986). The impact that the number of encounters has on satisfaction is used to measure the social impacts. Management must decide what levels of satisfaction are appropriate. If the impacts 
exceed the specified range set by management, then use levels and types of use are adjusted. Critics of social carrying capacity methodology question the appropriateness of using number of encounters as the sole determinant of social impacts, since many other factors also influence satisfaction such as the weather. Further, the process is complicated because it involves assumptions regarding behavioral and psychological attributes. Although carrying capacity is divided into four types, it must be remembered that they are all related. This study analyzes data collected in two surveys, 1986 by woods Hole Oceanographic Institute, and 1991 by the University of Rhode Island, providing information about the tourists. This study shows how this approach could not be applied in the Galápagos Islands and some of the problems that occur.

\section{Objective of the study}

The major objective of this research is to gather and analyze information regarding social carrying capacity in the Galapagos Islands. This information will help the Galápagos National Park Service and the new high level commission on tourism to maximize the value of the resources they are trying to manage. Results from this study can also be used to further our understanding of the significance of social carrying capacity as applied to management of tourist areas.

The study provides a description of the types of visitors in the two surveys and it answers the following 
questions: What are the visitors like? can a social carrying capacity study that looks at use levels and satisfaction be applied in the Galapagos? What are some of the problems with measures used for determining a social carrying capacity? Knowledge of this information is important to effective management. The research focuses on the relationships among satisfaction measurements and different use levels. These relationships are essential in determining social carrying capacities. To achieve the major objective, this research considers the general characteristics of the visitors, with measures of satisfaction and compares them to use levels. The critical aspects of social carrying capacity factors unique to the Galápagos Islands are summarized and recommendations for future social carrying capacity studies are presented. The following chapter describes the sample and the method used to analyze social carrying capacity in the Galápagos Islands. Chapter 3 presents a review of social carrying capacity related literature. Chapter 4 covers the history of the Islands, the climate, human impacts, the political issues, tourism, and a description of a visitor site. Use levels are discussed as well as some problems and conflicts between tourism and other activities. There are estimates of the other three types of carrying capacity. Chapter 5 presents the analysis of the surveys. Finally, Chapter 6 discusses critical aspects of social carrying capacity. 
CHAPTER 2

METHODOLOGY

\section{Surveys and Data}

The information for this thesis was gathered through a literature review at the University of Rhode Islands's library, two surveys conducted in the Galapagos Islands, and a two week visit to the Islands. Informal interviews were conducted with tourists, guides, tour operators, and local residents which provided a better understanding of the status of the tourism industry.

The Woods Hole Oceanographic Institute survey was conducted in 1986 (See Appendix 1). Permission to use the data was granted by Steven F. Edwards of the Woods Hole Oceanographic Institute. All responses were completed anonymously. The data was collected to determine the demand for Galápagos vacations, but the data used in this study had not been analyzed in this way before. It was written in four languages: English, French, Spanish; and German. The surveys were distributed by the naturalist and auxiliary guides who accompany each tour group. The guides distributed the surveys at the end of the tourists' vacation. The sample includes 361 returned questionnaires. The survey conducted by the International coastal Resources Management Program through the coastal Resources Center at the University of Rhode Island took place in 1991 (See Appendix 2). Permission to use the data was granted by Bruce Epler of the Coastal Resources Center. All responses 
were anonymous. The data is being used to determine the economic impact of Galápagos tourism on the Ecuadorean economy; at the time this thesis was being written, much of the data had not been analyzed. The sample includes 379 returned questionnaires. It was distributed to departing tourists at the airport in the Galápagos Islands.

\section{Method of Analysis}

A general description of Galápagos Islands tourists is given from the responses to these surveys. There is information on age, income, length of visit, places of origin, types of accommodations utilized and variables related to visitor satisfaction. It was originally intended that the 1986 and 1991 information on visitors would be compared to determine significant changes in that five year time period. However, the surveys were conducted at different times of the year by different people and in different locations. The result was two very different samples which makes direct comparisons inappropriate. The results are discussed and comparisons are made, but comparative statistical tests were not used.

In the 1986 survey, visitors were asked what was the maximum fee they would be willing to pay for the park entrance fee which, at that time, was $\$ 30$ for foreigners, and about $\$ 6$ for Ecuador nationals. Theoretically, a high level of satisfaction is reflected with a high willingness to pay. The willingness to pay variable was correlated while controlling for income. 
Correlations were calculated using the dependent variables of satisfaction and the number of groups encountered, satisfaction with the size of the tour groups, and satisfaction with nature and with the services. visitor satisfaction is analyzed to help determine the social impacts based on the number of encounters with other groups. This study shows how the use of one social impact measure, use levels on satisfaction, cannot be used in the Galápagos to determine the social carrying capacity. other ways to examine social carrying capacity are discussed.

\section{Limitations}

The surveys were administered differently which provides some limitations to the data. Although the type of information was similar, these surveys were not identical. There was no pre-test for either of the surveys, and as a result, some of the questions may not have acquired the intended information. The surveys focus on the Galapagos Islands as a whole while the social impacts vary with intensity of use at each of the sites. 


\section{CHAPTER 3}

\section{LITERATURE REVIEW}

\section{The Concept of Carrying Capacity}

Carrying capacity is a concept that is often used, but is often misused and criticized. Its meaning is elusive making its application in management programs difficult. Some critics of carrying capacity include Bury (1976), Burch (1984), and Washburne (1982). According to Shelby and Heberlein (1986), carrying capacity is related to specific management objectives and, within management objectives, there is a range of acceptable social impacts. There is no single value which is commonly regarded as carrying capacity. The results of studies in this area have not established the necessary relationships to support all of the Shelby and Heberlein approach, but many explanations are given in an attempt to understand the reasons for its failure.

Carrying capacity has been divided into a few different categories. Bury (1976) identifies three types, biological, physical, and cultural, while Shelby and Heberlein (1986) identify four, ecological, physical, facility, and social carrying capacity. Roughly, they include the same characteristics, except Bury has combined physical and facility into one category. According to shelby and Heberlein, ecological carrying capacity is concerned with impacts to the ecosystem. It examines how use levels affect plants, animals, soil, water, and air quality. The 
ecosystem impacts have certain standards that must be maintained according to management objectives, such as certain ratios of plant species. When the ratios have been changed by use of an area, the use level has exceeded the ecological carrying capacity and has caused negative ecosystem impacts. Management must intervene by restricting use levels or by limiting the pattern or type of use in a particular area.

Physical capacity refers to space impacts. The amount of space in natural areas is fixed. Visitor density is a measure; there is a maximum number of people able to fit in a particular area at one time. Management is responsible for setting acceptable standards (Shelby and Heberlein, 1986).

Facility capacity considers the occupancy of various facilities. It involves improvements that are intended to handle visitor needs. Visitor-staff ratio, percent occupancy for various facilities, and time waiting to use facilities are all included in this category.

Social capacity refers to impacts which impair or change visitor experiences. Bury's cultural viewpoint includes visitor satisfaction with an experience, which is also in Shelby and Heberlein's description of social capacity (Bury, 1976). "Social carrying capacity is the level of use beyond which social impacts exceed acceptable levels specified by evaluative standards" (Shelby and Heberlein, 1986:21). Types of social impacts include number of encounters with other groups in a wilderness area and 
their impact on enjoyment. The procedures for establishing a social carrying capacity are not well established but it is very important.

"Social capacity is often the most critical in the long run. Ecological impacts can often be mitigated by management parameters other than use level, physical capacity is usually quite high, and facilities can be expanded or made more efficient" (Shelby and Heberlein, 1986:144).

Shelby and Heberlein (1986) have identified three conditions that are necessary for determining social carrying capacity. First, there must be a known relationship between use level or other management standards and social impacts. Second, there must be agreement among relevant groups about the type of experience to be provided. Third, there must be agreement among relevant groups about appropriate levels of social impacts.

An important point in this approach is that reduction of use levels is not the only solution. For example, if tourists are dissatisfied due to large crowds at a particular visitor site, management could impose a fixed schedule that would allow the same total number of visitors but keeps the maximum number visitors at any one time below a certain level. They could also change the appearance of the visitor site by planting trees or bushes so that visitors would not be able to see other visitor groups, thereby reducing or eliminating the perception of crowding.

within management objectives, there is a range of values that is considered to be acceptable. Most of the relevant articles suggest that carrying capacity is not an 
absolute value that needs to be determined (Graefe et al., 1984a). Shelby and Heberlein discuss this approach in a recreational setting. A minimum level might be the number of visitors required to keep a facility open. A maximum level would be reached when a facility was full. For example, an auditorium is full when people are standing in the aisles. An optimal level would be below the maximum since it may be dangerous and uncomfortable for visitors to be standing and blocking the aisles. It is the determination of optimal capacity that is difficult because it involves subjective and evaluative judgements that say one thing is better than another (Shelby and Heberlein, 1986). Optimal levels are also difficult to determine in wildlife settings because value judgements are required.

\section{Problems with Carrying Capacity}

Bury (1976) argues that carrying capacity is a difficult management tool, and if it is misapplied, it may greatly distort current and potential values of recreation areas. It is very complex for managers to attempt a comprehensive approach to determine biological, physical and social capacities. A comprehensive carrying capacity study should not be done because it is time consuming and may be misleading. If managers accept the lowest capacity, then many values may not be fully utilized.

Bury also points out several misconceptions. First, there is a belief that the manager's responsibility is primarily to the resources rather than the people, but the 
needs of the resources and the people must both be considered and met. A second misconception is that each area of land has a limited durability. Bury points out that this is not the case (1976); there are means available to extend the durability of sites, such as the use of supplemental planting to create the illusion of a larger site. A third misconception discussed by Bury is that recreation areas would be much easier to manage if only the carrying capacity was known. It is very difficult to determine a capacity, and if it were established, there would still be conflicts regarding proper use intensities. Washburne (1982) interprets the concept of carrying capacity differently from Shelby and Heberlein. He agrees that setting standards according to management objectives and monitoring conditions is effective, but the calculation of a use capacity is not effective. He believes that a reduction of use levels is not the only solution. Unacceptable conditions may be corrected in many different ways. Changing the pattern or type of use may be more effective than limiting use.

Burch (1984) is very critical of the concept but is looking for answers that carrying capacity is not designed to answer. "While research can help managers who are concerned with carrying capacity, it cannot supply answers about what the carrying capacity of a site is or should be" (Stankey, 1979 in Burch, 1986:490). Burch describes carrying capacity as a term borrowed from wildlife ecology and range management which is not applicable to people. In 
wildlife management, the effort is directed at enhancing and increasing the capacity of the range and the size of the herd (Burch, 1984), but when applying the same concept to people, it is used to limit participants in a particular use (Burch, 1984). This is incorrect since limiting use is only one solution.

\section{Earlier Studies}

In the many studies done in this field, there has been little success in meeting Shelby and Heberlein's rule that there is a known relationship between use levels and social impacts. There is a low statistical association between encounters and satisfaction, the most common variables used to measure social impacts. The low level of association is explained by expectancy theory, discrepancy theory, social interference, stimulus overload, coping strategies, and recreational displacement.

Expectations influence the perception of recreation experiences for visitors. There may be specific expectations such as a pristine environment, or general expectations such as stress release, relaxation, or learning (Graefe et al., 1984a). Some of the expectations are shared with others and are social norms, whereas others are personal norms.

Most people participate in recreational activities to satisfy multiple expectations, but every individual has a different combination of expectations. First time visitors to an area have inaccurate expectations, while repeat 
visitors may have very specific expectations based on earlier experiences (Manning and Ciali, 1980). Results of a study of fishermen, swimmers, and rafters, showed that first time visitors were not negatively affected by higher uses. Vaske et al. (1980) found similar results in a study of boaters at a lake. Repeat visitors perceived increases in visitor numbers more negatively than first time visitors. In discrepancy theory, visitors compare perceived outcomes from an experience with the rewards that were expected. Overall satisfaction is affected by the amount of discrepancy (Graefe et al., 1984a). Social interference and conflicts among users occur when the presence of other individuals interferes with the goals of the visitor (Graefe et al. 1984a). Stimulus overload occurs when the level of social interaction exceeds the level desired by the individual which results in a perception of crowding (Graefe et al., 1984a).

Studies show that there is not a predictable response by visitors to varying use levels, but there is a connection between the number of visitors in an area and the rate of contacts between visitors. The increased interaction usually results in increased perceptions of crowding, which may or may not result in decreased visitor satisfaction (Graefe et al., 1984a).

There is a distinct difference between density, which is a measure of the number of people per unit area, and perceived crowding, which is a psychological evaluation of density (Gramann, 1982). Desor (1972) performed a study 
that demonstrated that changes in surroundings, while keeping densities constant, affected perceptions of crowding. However, in a recreation setting, Ditton, Fedler, and Graefe (1983), found that crowding is related more to visitor's expectations, preferences, and previous experiences than to actual or perceived encounter levels. They concluded that crowding is related to many variables besides the number of people encountered (Ditton, Fedler, Graefe, 1983).

People use coping strategies to reduce the potential negative effects of visitor densities (Gramann, 1982; Ditton et al., 1983; Shelby and Heberlein, 1986). Individuals may modify their expectations and preferences as a means of reducing the negative effects of perceived crowding. Manning and Ciali (1980) relate this to cognitive dissonance. Visitors rate recreation experiences high, regardless of actual conditions in order to reduce internal conflict.

Another explanation for the low level of association between use and satisfaction is recreational displacement (Graefe et al., 1984a; Manning and Ciali, 1980) which occurs when individuals change their behavior in response to increases in density and crowding. An individual who prefers solitude may become dissatisfied with increasing numbers of people, and that individual will avoid the area and select a new one that meets his needs. The user who moves on to a less crowded area is displaced by users with norms that are more tolerant of higher densities. 


\section{Summary}

The literature review by Graefe et al. (1984a) indicates that research on recreation has ambiguous implications. They feel that research concerning social carrying capacity is in its primitive stages and that extensive work needs to be done in the area. Shelby and Heberlein (1984) disagree by stating that significant' advances have been made in the last ten years. More than sixty studies have been conducted and the basic theoretical model has been articulated. They agree that problems still remain, but great progress has been made.

Stankey and McCool (1984) find that an important point in understanding social carrying capacity is that there is an inherent variation in tolerance among individuals and user groups. The real issue is under what conditions are use levels or encounters the salient point in social carrying capacity. Becker et al. (1984) and Graefe et al. (1984b) agree that, so far, social carrying capacity has failed to provide management with a system for allocating use and implementation. 


\section{CHAPTER 4 \\ THE GALAPAGOS ISLANDS AND TOURISM}

\section{History}

The Galápagos Islands have enjoyed a rich history during the years since their discovery in 1535. Visitors have included pirates, whalers, fur seal hunters, scientists, the military, convicts, fishermen, and now tourists. All have had an impact on the Islands.

In 1535 the Galápagos Islands were officially discovered by Fray Tomás de Berlanga, the Bishop of Panama. The ocean currents carried his ship out to the Islands during a voyage from Panama to Peru. In correspondence, he described the giant tortoises, the iguanas, and the unusually tame birds. The Islands appeared on a map in 1570 as "Insulae de los Galopegos" which means the Islands of the Tortoises. They were also called the "Encantadas", meaning the Bewitched Islands (Jackson, 1985). The garua, a form of fine fog, also created the impression that the islands would disappear.

From the late 1500 s to the early 1700s, the Galápagos Islands were primarily used as a refuge for raids on spanish Colonial ports. In the late 1700 s to the early 1900 s whalers and sealers frequented the Galápagos Islands. Tortoises were the main source of nutrition for the whalers. Tortoises are able to live for extended periods of time in confined quarters with little food and water making them quite useful to sailors. There are some reports that the 
tortoises survived for periods longer than a year. This provided whalers with fresh meat during their long trips away at sea (Epler, 1987). It is estimated that at least 15,000 tortoises were taken between 1811 and 1844 and that probably more than 100,000 were taken altogether (Jackson, 1985). The tortoises are protected now, but certain populations are extinct on some of the islands and found in very small numbers on other islands. In 1974, total populations were estimated between 5,200 and 9,100 (Epler, 1987).

The Galápagos were annexed by Ecuador in 1832. A colony was established on Floreana as a penal settlement. Settlements were repeatedly attempted but they all failed. An enduring settlement was not founded until 1893. In 1892, the islands were renamed "Archipiélago de Colón" in honor of the 400 th anniversary of the discovery of the Americas by Christopher Columbus. The Galápagos is the most commonly used name (Jackson, 1985).

Charles Darwin is one of the most widely known visitors to the Galápagos. His voyage on the HMS Beagle allowed him to make observations and collect samples which led him to the subject of evolution, and subsequently his book, origin of the species in 1859. The basis of his book went against most thoughts and beliefs in the field of biology current at the time. Although not well accepted then, it now provides the basis of modern biological thought.

The islands have also been used for military purposes. During World War II, the United states built an air base on 
Baltra Island. It was used to patrol vessel movement through the Panama Canal (Jackson, 1985). The air strip is used commercially now.

\section{Geography}

The Galápagos Islands are made up of thirteen large islands, six smaller islands, and over forty islets that have official names. They are shown in figure 4.1. Isabela is the largest island with a land area of $4,588 \mathrm{sq} \mathrm{km}$. Its highest point is $1,707 \mathrm{~m}$. Santa cruz is the second largest with a land area of $986 \mathrm{sq} \mathrm{km}$ and highest point of $864 \mathrm{~m}$. Mainland Ecuador is $960 \mathrm{~km}$ to the east. Total land area is $8,000 \mathrm{~km}^{2}$. The depth of the ocean drops off quickly to $3,000 \mathrm{~m}$ as one moves away from shore. All of the islands were formed by volcanoes. Presently, volcanic activity is still observable in some locations (Broadus et al., 1984). 


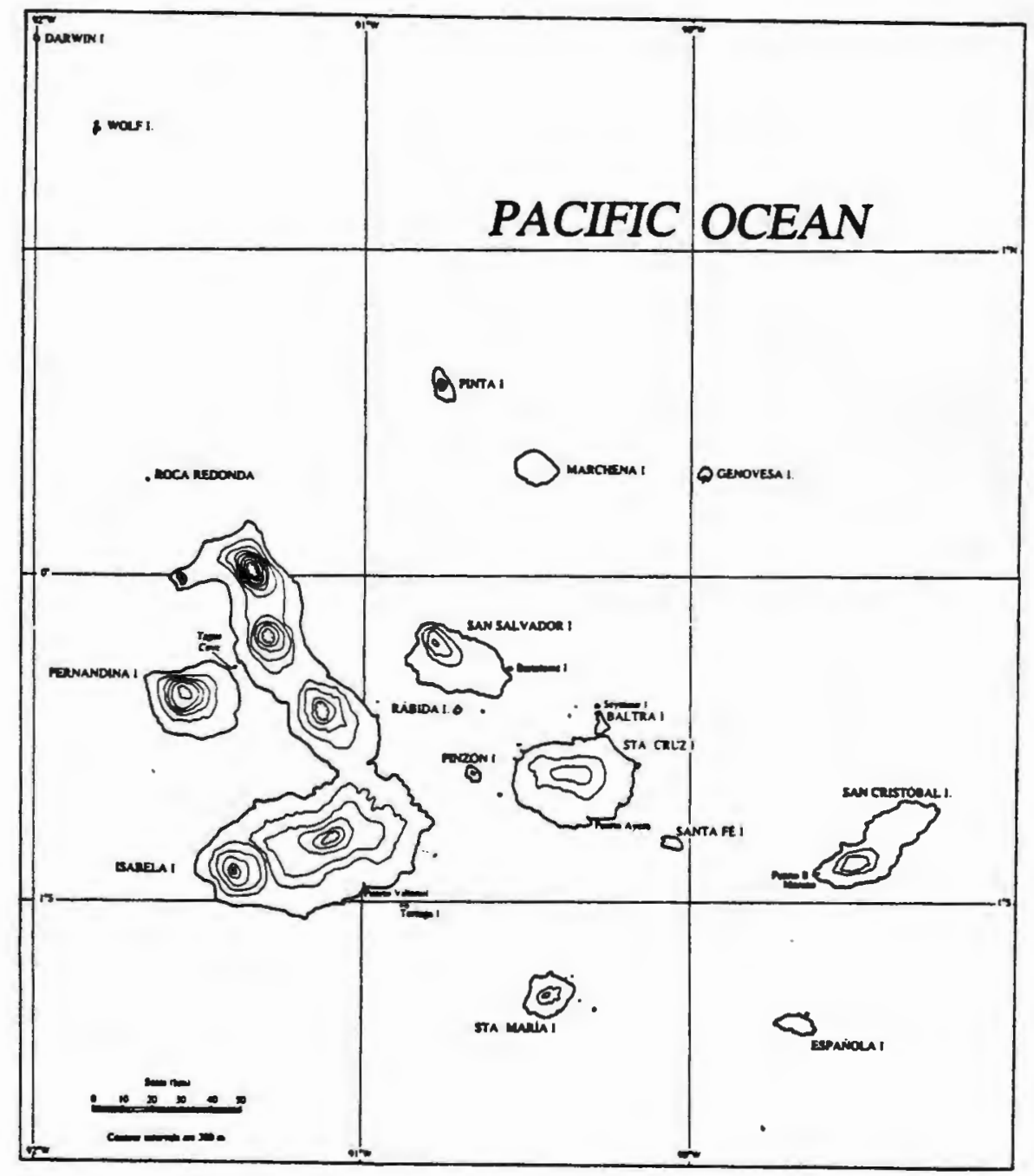

Figure 4.1 Map of the Galápagos Archipelago
Source: Jackson, 1985

Climate and Environment

There are two seasons in the Islands. From January to June, the air temperatures are warm with clear skies and occasional heavy rain showers. It is known as the warm/wet season. The sea is usually calm. From June to December the air is cooler with overcast skies and heavy rains in the highlands but none in the lowlands (Jackson, 1985). The sea 
is often choppy. Between seasons, weather is unpredictable. Since the Galápagos are far from other land masses, the climate is determined by the ocean currents.

In some years, the flow of warm water is much greater which results in an "El Niño" year. Sea surface temperatures are higher and rainfall increases. The warming of the surface waters pushes the nutrient rich cool water of the thermocline into deep waters. As a result, productivity is very low. The 1982-83 El Niño set new records. It was associated with droughts in Australia and Africa, cyclones in French Polynesia, and intense storms along the Pacific Coast of North America. Sea surface temperatures were 4 degrees celsius above normal from December 1982 until May 1983, and then increased to 5.5 degrees above normal. By September 1983, temperatures had returned to normal (Robinson, 1987).

The hardest hit were the seabirds since they rely on cool productive waters for food, and they experienced breeding failures. Sea lions, fur seals, and marine iguanas were also affected. Breeding failure was common and mortality rates increased due to the reduced food supplies. News of the impacts of El Niño travelled to the tourism industry around the world. Tour operators requested reports regarding the impacts on the popular species such as the birds, sea lions, and iguanas, and as a result, there was a decrease in tourist arrivals for 1985. 


\section{Human Activities}

The Galápagos islands are undergoing changes as a result of increased tourism. Introduction of non-indigenous species, and the general pollution problems associated with the ever increasing human populations are adversely affecting the environment. These negative impacts are recent but humans have had an effect on the islands for hundreds of years.

In 1959, the Galápagos National Park (PNG) was established. Most of the land in the islands is owned by PNG, but $3.3 \%$ is reserved for human settlements. Most of the land area was designated as protected park areas to maintain the ecological integrity of the islands and protect them from harmful development projects. See Table 4.1 for distribution of land.

Table 4.1

Distribution of Land

Agricultural

Urban

Strategic

Total Area for Colonization

National Park

Total

Source: Epler, 1990
Area(ha) Percent

\begin{tabular}{rc}
23,269 & $2.95 \%$ \\
387 & $0.05 \%$ \\
2,700 & $0.34 \%$ \\
\hline 26,356 & $3.34 \%$ \\
761,844 & $96.66 \%$ \\
\hline 788,200 & $100.00 \%$
\end{tabular}

There are human settlements on four of the larger islands, Isabela, Floreana, Santa Cruz, and San Cristóbal. Puerto Baquerizo Moreno on San Cristóbal is the capital but 
most visitor activities occur in Puerto Ayora on Santa cruz Island. The Charles Darwin Research station and the Galápagos National Park service are located just outside of Puerto Ayora (Jackson, 1985). According to the census in 1990, the population of all four islands is 9,749. The population distribution is shown in Table 4.2. Santa Cruz has the largest population with 5,305 inhabitants, and san Cristóbal is second with 3,481. Populations are now estimated at 6,000 in Santa Cruz, and 4,000 in san cristóbal (Interview with Milton Aguas, Candidate for Governor of the Galápagos Islands, March 4, 1992). The population of Isabela and Floreana is smaller. Table 4.2 shows the distribution.

Table 4.2 Distribution of Human Populations, 1990

\begin{tabular}{|c|c|c|c|}
\hline & Urban & Rural & Total \\
\hline San Cristóbal & 2,920 & 561 & 3,481 \\
\hline Santa Cruz & 4,292 & 1,013 & 5,305 \\
\hline Floreana & 0 & 104 & 104 \\
\hline Isabela & 697 & 162 & 859 \\
\hline Total & 7,909 & 1,840 & 9,749 \\
\hline
\end{tabular}

Source: SPNG, 1990

Approximately $3 \%$ of the total land mass, or $90 \%$ of the land designated for human use is for agriculture. Crops include onions, cabbage, beans, potatoes, bananas, avocadoes, coffee, and some citrus fruits. Cattle ranching is also an important activity. Intensive farming does not take place due to the unsuitable nutrient poor soils (Epler, 1990) 
Employment is categorized as agriculture (including fishing), manufacturing, construction, commerce, transportation, services, and others. See table 4.3 for employment in 1974 and 1982. There was an $11 \%$ decrease in agriculture, but all other activities experienced growth. Construction grew by $282 \%$ which was the largest change. The total labor force grew by $54 \%$. The largest employment sector is services which represents $43 \%$ of the labor force (Epler 1990:13).

Table 4.3 Distribution of Employment

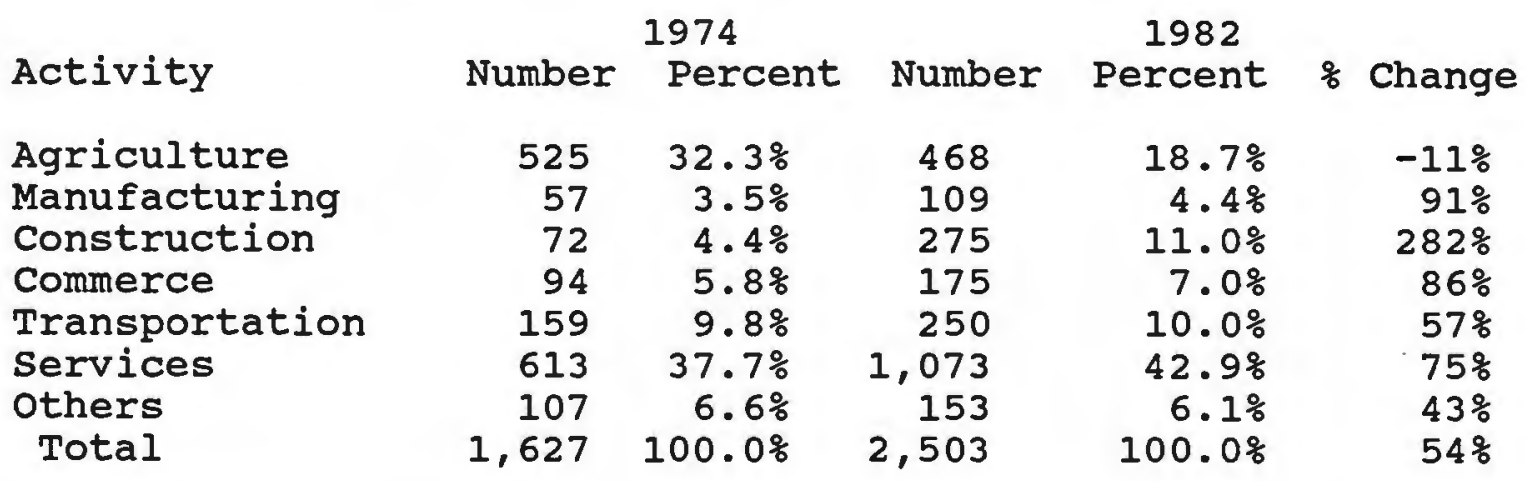

Source: Epler, 1990

There is an artisanal fishery for "bacalao", also known as cod. There are also fisheries for mullet and lobster. The bacalao is salted and dried and shipped to the mainland, while the mullet and lobster is captured mainly for local consumption, tourists and residents. The number of fishermen has decreased since job opportunities in the tourist industry have higher economic returns. Many fishermen have converted their boats into tour boats 
(Broadus et al., 1984).

\section{Political organization}

Ecuador exercises sovereignty over the ocean space of a 200 mile territorial sea. It is measured from archipelagic baselines. The water inside the baselines is considered internal waters. Since the territorial sea is accepted as 3 miles in other countries, some countries do not recognize the 200 miles as a legitimate claim.

The Galápagos Province was created in 1973. It divided 16 major islands and islets into three districts. There is San Cristóbal, Santa Cruz, and Isabela. San Cristóbal was designated the capital of the province. Each district represents a municipality designed to perform specific functions such as planning and development. One of their. objectives is the preservation of the unique flora and fauna. Most of the area is under the administration of the Ministry of Agriculture. The Municipalities only have control over the colonized areas.

The Galápagos National Institute (INGALA) was created in 1980 for planning and coordination of developmental activities. INGALA's role is to provide technical and financial assistance to other institutions and regulate activities in the archipelago. The President of Ecuador may 'nominate and remove INGALA's manager as he pleases (Broadus, et al., 1984).

Coastal management in the Galápagos is a challenge. Jurisdiction over the coastal areas is fragmented among 
different institutions with some overlapping authority. Under the Ministry of Defense, the Navy is responsible for military defense, and Port Captains control maritime traffic, coastal use permits, and some marine environmental protection. The Ministry of Agriculture regulates the National Park Service for the conservation of the land habitat. The National Tourism Authority (DITURIS) regulates tourism under the Ministry of Industry and commerce. The Ministry of Natural Resources and Energy control the National Fisheries Authority which includes the Subsecretariat of Fisheries Resources. Overall development policies are managed by INGALA (Broadus et al., 1984). Table 4.4 shows the different jurisdictions and authorities. A main goal of the Galápagos National Park (PNG) is to govern the use of park areas in an attempt to preserve indigenous and endemic species and the environment that supports them. The PNG has facilitated the scientific studies, and it is evident from the increases in numbers of references compiled at the Smithsonian Institution since its establishment in 1959. 
Table 4.4 Coastal and Marine Area Jurisdictions Organization Duties

INGALA

- Oversees all other organizations and activities from offshore fishing to inland development activities. Includes national park areas as well as municipal areas.

Ministry of Defense

$\begin{aligned} \text { Navy } & \text { - Military defense } \\ \text { Port Captains } & \text {-Trafic control, coastal use permits, } \\ & \text { environmental protection. National park } \\ & \text { areas and municipal areas. }\end{aligned}$

Ministry of Agriculture

National Park Service

-Activities in land area only in national

park areas.

Ministry of Industry and Commerce

National Tourism Authority (DITURIS)

-Regulates tourism, transportation.

Municipal areas.

Ministry of Natural Resources and Energy

National Fisheries Authority

-Regulates fisheries activities inside the park areas and municipal areas.

Source: Broadus et al., 1984.

\section{Tourism}

To accommodate tourism, and protect the environment, the PNG has established over forty visitor sites. The Park has been classified into five zones. The primitive, scientific zones are free of introduced species. The goal is to maintain the ecological integrity. Access is restricted to scientific investigations with special permission from the PNG. The primitive zones are areas where there has been some alteration but are maintained to 
allow recuperation. Eradication of introduced species is a goal in this zone. Zones of special use are areas that have supported strong alteration and extraction activities. Special use zones are permitted but they are fixed in area. The last two, extensive and intensive use zones involve tourism. Extensive use zones allow a maximum of 12 persons at any one time. These sites are to give the visitor the opportunity to enjoy a quiet and natural state without interference from big groups. Intensive use zones were selected because they give a representative example of the Galápagos communities. These are the only places that are able to support constant visitors (Cifuentes, 1984). At each of the sites there are trails and markers indicating boundaries. The objective is to keep the people away from the animals and to minimize the human impacts and keep it in small areas.

Certain visitor sites receive most of the visitors because the large ships favor certain sites and the smaller boats have a limited range. Table 4.5 shows some of the visitor sites and number of visitors during 1989. Figure 4.2 is a map showing all the visitor sites.

All visitors must be accompanied by a naturalist guide or an auxiliary guide. The guides must go through training, and most are able to speak a second language but it is not a requirement. The naturalist guides have more extensive training than the auxiliary guides. The auxiliary guides have been a weak point in the park system, a fact which has been confirmed by many discomforts expressed by visitors in 
Table 4.5

Number of Tourists Visiting selected sites within the

Galapagos National Park during 1989

Visitor site

Plaza Sur

Seymour Norte

Bartolome

Punta Suarez

Punta Cormorant

Rabida

Santa $\mathrm{Fe}$

Puerto Egas

Punta Espinoza

Caleta Tagus

Bahia Sullivan

Playa Las Bachas

Bahia Darwin

Caleta Tortuga

Bahia Gardner

Bahia Del Correo

Sombrero Chino

El Barranco

Daphne

Isla Mosquera

Playa Espumilla

Volcan Alcedo

Caleta Bucanero

Punta Garcia

Cerro Tijeretas
Number of Tourists

25,251

24,050

21,334

17,331

15,001

14,130

12,769

12,001

10,379

10,272

8,151

7,915

7,673

7,068

5,401

5,231

3,532

3,450

1,252

1,150

729

685

629

132

117

Source: SPNG, 1991

letters to the PNG. A major complaint has been the language barrier (Cifuentes, 1984). As the primary contact with visitors, the guides are responsible for ensuring protection of the plants and animals, and this is where the system is inadequate.

While visitors are at the designated visitor sites, they are required to stay within the designated areas. sites and trails are marked to indicate the boundaries. This system seems to work well most of the time, but in 


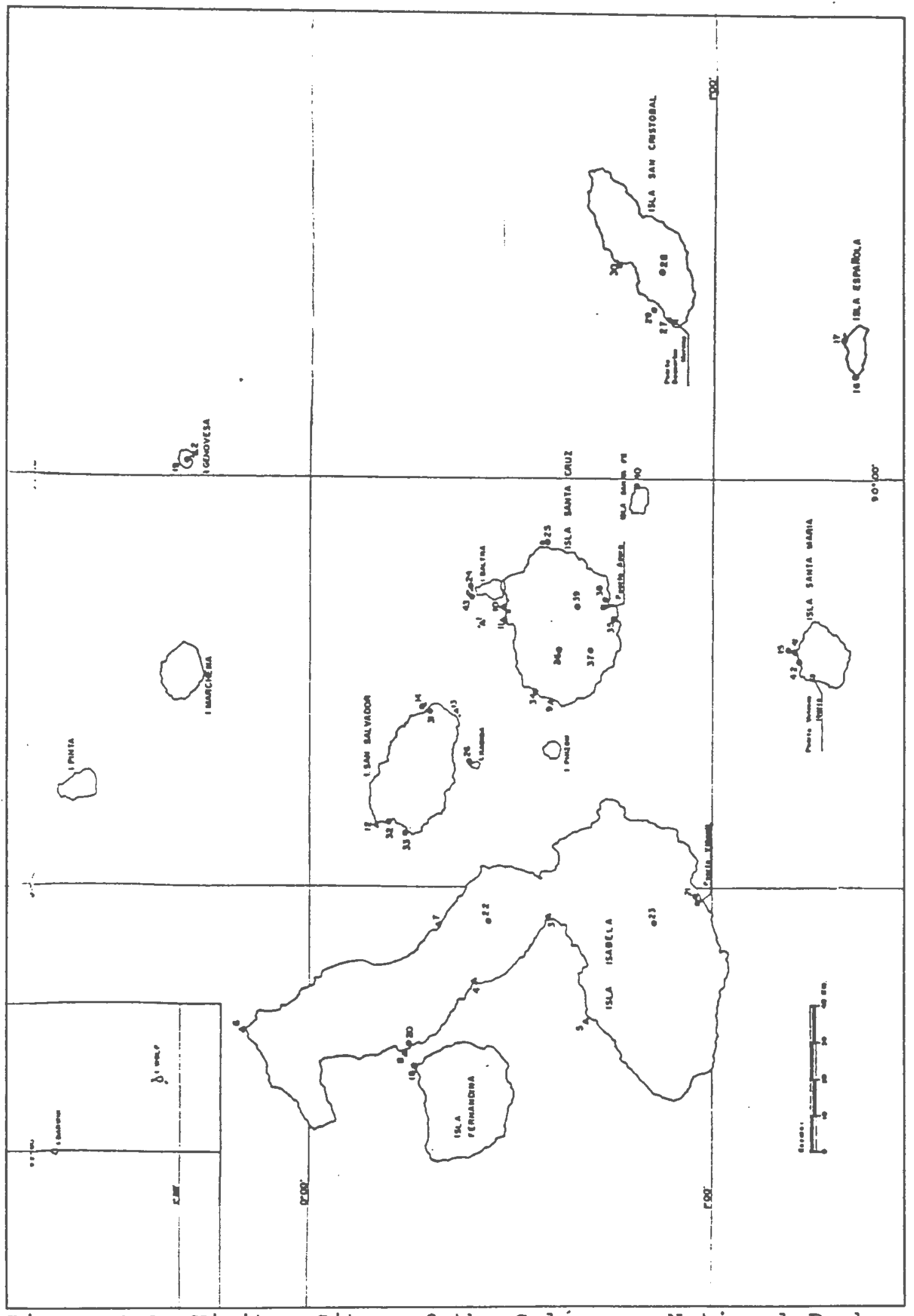

Figure 4.2 Visitor Sites of the Galápagos National Park Source: Cifuentes, 1984 
recent years, the PNG has not been able to keep up with the increases of visitors. Overcrowding occurs at some of the most popular sites, and erosion has been a problem in many sites (Emory, 1989).

One site, which is a good example of an intensive use visitor site, Bartolomé, is described. See Figure 4.3 for a map. This site was in the top three in 1989 for number of visitors. It gives the reader an idea of what a visitor may experience. Bartolomé Island is a small island adjacent to Santiago Island, also known as James Island. There is a dry landing and a trail to the summit with an elevation of $114 \mathrm{~m}$ located at number 5 on the map. There are various plants as well as lava tubes. The wet landing is located near number 1 on the map. There is a trail to south beach through mangroves and dune vegetation, turtles, sharks, and herons are usually present. At north beach there is swimming and snorkeling. At Pinnacle Rock on Bartolomé, there are often pengui.ns (Jackson, 1985). 


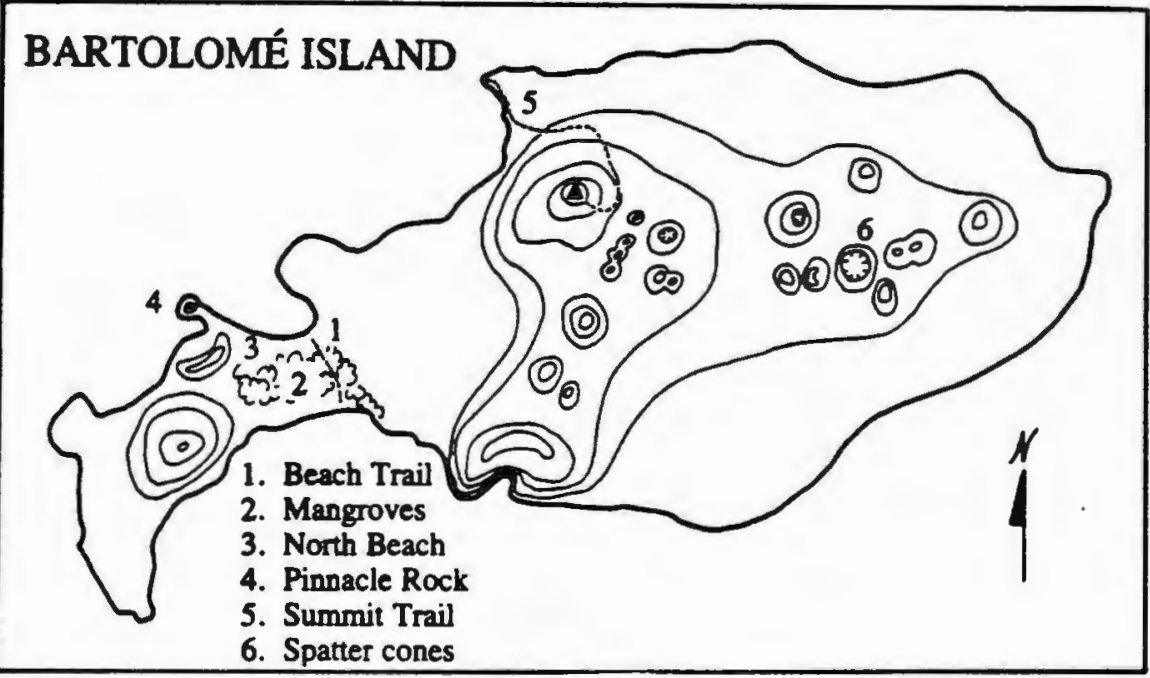

Figure 4.3 Bartolomé Island

Source: Jackson, 1985

\section{Human Impacts}

There have been increasing impacts on the environment. Marine pollution and small oil spills pose an increasing problem, and with growing numbers of visitors there is more boat traffic and an increasing input of normal operational discharges (Broadus et al., 1984). Garbage from tour boats easily finds its way into the water. A gust of wind can 
blow garbage overboard.

The introduction of species is also a concern for the PNG. Most plants and animals in the Galápagos evolved without natural predators. The introduced species have competed with and often killed the native plants and animals. Alien species are the target of eradication programs by the PNG (Emory, 1989). Cats, dogs, pigs, and goats were left in the islands by the whalers. Inadvertently, mice, rats, and insects were brought ashore as well. Introduction of alien species is still a threat, but precautions are taken to minimize the risk, such as the lightering of freight, but there is always a risk (Broadus et al., 1984). The PNG is working to eliminate the pests and re-introduce native species to some of the islands where they have been wiped out.

Scientific studies through the Charles Darwin Research Station do not show noticeable impacts on flora and fauna due to tourism; nevertheless, long time residents and guides have observed some changes. The albatross at Punta suarez have moved their nesting sites away from tourists paths. Sea lions on Isla Lobos have become increasingly nervous and aggressive towards tourists and some chase after tourists who come too close. Path erosion is a problem on Bartolomé, Caleta Tagus, Santa Fé, Plaza Sur, and seymour Norte. Some marine turtles have been reported to swallow plastic bags that resemble their jellyfish diet; consequently, the turtles die from blocked digestive systems. Feeding the animals is also a problem. Finally, black coral is 
harvested and sold in many of the souvenir shops in santa Cruz and San Cristóbal (Boo, 1990b). Black coral souvenirs from the Galápagos can also be bought in Guayaquil, in mainland Ecuador.

There has been a simultaneous growth in numbers of hotels and a growth in demand for day boats and trips to areas close to Puerto Ayora and Puerto Baquerizo Moreno. The park guidelines require that all boats be approved beforehand and register the visitors and destination. In one reported case in 1988, some Galápagos researchers were working at Plaza Island when several day boats arrived with passengers. The boats lacked the proper facilities, and upon arrival, the visitors hurried to the nearest cactus or outcrop of lava to relieve themselves. In the process, they crossed over terrain protected for the land iguanas. Those boats were not approved to go there, in addition, all boats going to Plaza Island are required to have latrines (Emory, 1989).

Although the system is strict, it apparently does not have the necessary enforcement capabilities. The Park Service is underfinanced. Former director Miguel Cifuentes believes that the Park service must grow with the number of visitors and it has failed to do that because it lacks the money (Emory, 1989).

\section{Transportation}

Currently there are two operating airports. One in Baltra, and one on San Cristóbal in Puerto Baquerizo. A new 
airport is under construction near Puerto villamil on Isabela Island (Broadus et al., 1984). The addition third airport will facilitate the growing number of visitors.

The urban areas are all located on the coast offering easy access to the harbor facilities. The existing harbors are shallow and are unable to accommodate large ships. There are docks, but they are too small. The principal harbor for the islands is run by the Navy at Baltra. The dock facility has deep enough water for moderate sized vessels. At this port, water, gasoline, and diesel are sold. At the other harbors, larger vessels remain outside the harbor while freight is lightered back and forth.

The number of tour boats operating in the Galápagos has grown over the years. Currently, there are 9 boats with fixed itineraries, two of which have a capacity of 90 persons. There are 45 boats that operate without a fixed itinerary and have capacities ranging from 4 to 14 persons. There are 17 boats that operate on a daily basis. Passengers on these boats stay overnight in the local hotels. The capacity of the day boats range from 10 to 20 persons.

\section{Conflicts Between Tourism and Other Activities}

Along with the growth of tourism, there has been a growth in the resident population and the urban areas. The trend to convert fishing boats to tour boats has left very few fishermen in operation. Most fish that is caught is 
bought by the tour boats before it gets to shore. The result is seafood shortages for residents and an economy that is dependent upon food supplies from the mainland (Emory, 1989).

In Puerto Ayora, the surge in the population growth has resulted in social problems. Miguel Cifuentes noted an increase in robberies and public drunkenness. The problems that they are experiencing are similar to those experienced anywhere there is a rapid population growth.

Fresh water resources are in short supply. Very little fresh groundwater is available; most water is caught in large tanks as it drains off rooftops in the rainy season. The municipal water supply is pumped from a local aquifer, but the water is brackish and can only be usej for bathing and cleaning (Emory, 1989). Drinking the water may be very hazardous to your health. In addition, sewage disposal poses an increasing problem as populations grow. The waste from sewage disposal sites tends to channel into the same fissures that conduct groundwater (Broadus et al., 1984). In San Cristóbal, there is a pipe that disposes sewage right in the middle of the waterfront.

Electricity is provided by a set of diesel generators in Puerto Ayora. Under normal conditions, power is available from 6:00 am until midnight. Local residents, however, feel that there is not enough power for everyone. one resident pointed out that the street lights had not been lit for over a year (Emory, 1989).

Another problem is the removal of sand for cement 
production. Although this is considered bad practice and is prohibited, it still occurs. Beach areas within the park but in close proximity to Puerto Ayora have been shrinking. Puerto Ayora used to be fringed by several small beaches, but they are gone. The cement is used by new immigrants to build homes (Emory, 1989).

\section{Visitor Levels}

The annual flow of visitors to the Galapagos National Park fluctuates from year to year. In recent years, the percentage of Ecuador nationals visiting the park increased to over 50 percent. The percentage of foreign visitors has gradually declined over the years. The large increases in visitors occurs in years when a large passenger ship was introduced, and when the second airport was opened on San Cristóbal. Table 4.6 shows growth from 1974 through 1990.

Table 4.6 National and Foreign Visitors to Galápagos National Park, 1974-1987

$\begin{array}{rrrrrrr}\text { Year } & \text { Nat'I } & z & \text { Foreign } & \% & \text { Total } & \text { \% Change } \\ 1974 & & & & & 7,500 & \\ 1975 & & & & & 7,000 & -6.7 \% \\ 1976 & 863 & 13.7 \% & 5,432 & 86.3 \% & 6,295 & -10.0 \% \\ 1977 & 1,349 & 17.3 \% & 6,439 & 82.7 \% & 7,788 & 23.6 \% \\ 1978 & 1,606 & 13.1 \% & 10,693 & 86.9 \% & 12,299 & 57.9 \% \\ 1979 & 2,226 & 18.9 \% & 9,539 & 81.1 \% & 11,765 & -4.3 \% \\ 1980 & 3,980 & 22.8 \% & 13,465 & 77.2 \% & 17,445 & 48.3 \% \\ 1981 & 4,036 & 24.8 \% & 12,229 & 75.2 \% & 16,265 & -6.8 \% \\ 1982 & 6,067 & 35.4 \% & 11,056 & 64.6 \% & 17,123 & 5.3 \% \\ 1983 & 7,254 & 41.1 \% & 10,402 & 58.9 \% & 17,656 & 3.2 \% \\ 1984 & 7,627 & 40.4 \% & 11,231 & 59.6 \% & 18,858 & 6.8 \% \\ 1985 & 6,279 & 35.2 \% & 11,561 & 64.8 \% & 17,840 & -5.4 \% \\ 1986 & 12,126 & 46.6 \% & 13,897 & 53.4 \% & 26,023 & 45.9 \% \\ 1987 & 18,000 & 55.4 \% & 14,500 & 44.6 \% & 32,500 & 25.3 \% \\ 1988 & & & & & 40,745 & \\ 1989 & & & & & 41,899 & \\ 1990 & & & & & 41,192 & \end{array}$

Source: Boo, 1990b; SPNG, 1991 
There is also a monthly variation in visitors. April, August, and september are peak periods for national visitors, while January, March, July, and August receive peak numbers of international visitors. Overall, the peak months are January, April, and August (B00, 1990b).

In PNG records between July of 1986 and June 1987, United States visitors represented 28.7 percent of total arrivals. Germans represented 6.8 percent, Swiss made up 3.2 percent, Italians 3.1 percent, Canadians 2.7 percent, and visitors from other Latin American countries represented 2.1 percent (Boo, 1990b).

In a survey by the World wildlife Fund in 1987, a slightly higher percent of visitors, 55 percent, were male. The mean age was 40 , and the mean annual income was USD\$40,000 (BOO, 1990b).

The reasons for visiting the Galápagos included viewing rare species ( 77 percent), fauna (70 percent), flora (42 percent), geology (42 percent), adventure (31 percent), and recreation (13 percent). Over $83 \%$ of those surveyed used a boat as their accommodation (Boo, 1990b).

Each visitor's experience may be quite different. Cruises last from 1 day to two weeks, and different boats have different schedules. The weather varies, and the animals are unpredictable as well. Many visitors to the Galápagos Islands combine their trip with visits to other places in South America. Some visit with the Galápagos as their sole destination.

Visitors who fly into San Cristóbal board boats where 
they stay for the duration of their trip, or stay in one of the hotels. Visitors who fly into Baltra are transferred to their boats or are transported to Puerto Ayora on Santa Cruz. A majority of visitors stay on the boats, but there is a growing use of the hotels and day boats.

Foreign visitors pay a fee of $\$ 80$ to the park upon arrival in the Islands. The pricing policy allows Ecuador nationals to pay less for airfare and for the park entrance fee (Epler, 1990). Currently, nationals pay about 10,000 sucres. The Galápagos Park represents a source of income for the Ecuador Park system, however, less than 50 percent of the revenues from park fees are kept in the Galápagos to maintain the park. The rest of the money goes to the National Park Service to be distributed among all parks in Ecuador (Emory, 1989).

\section{The Visitor Experience}

At each individual visitor site, different plants, animals, and landscapes can be expected. Swimming and snorkeling are possible, scenic walks along the trails, and photographing exotic and rare species. The sites that are not as heavily visited are usually further away or characterized by rough and difficult terrain. Some of the visitors come to the Galápagos seeking an adventure. Alcedo Volcano on Isabela Island is a site that requires an overnight hike. There are giant tortoises and hawks and fumaroles where steam from volcanic activity is visible (Jackson, 1985). The Galápagos Islands visitor sites can 
meet the needs of a young group of people seeking an adventure and an older group seeking a relaxing learning experience.

Ideally, each of the visitor sites receives only a few groups a day. Each site is unique; some may have long trails so that when a group is at one end, they are unaware of groups at the other end. Other sites may be smaller making it more obvious that other groups are present.

As the situation currently exists, the visitor sites closest to Puerto Ayora and Puerto Baquerizo Moreno are visited heavily because they are easily accessed by the day boats. The result is crowding at some of the sites. Minimally, visitors should not have to wait too long behind other groups at a site. Problems occur when a 90 passenger vessel disembarks at a visitor site. The group divides into smaller groups of about 15 persons. The 90 passenger boats are on fixed itineraries and ideally no other boats should be at that site at the same time.

The larger boats are more luxurious, and tend to cater to older people. Their facilities meet the needs of people who are not as physically capable of climbing on rough terrain. With more passengers on the large boats, it is more likely that people will be aware of more visitors at the sites. The people would be expecting to see other people since their boat is so large. On the other hand, a group of adventure seekers may be very dissatisfied if they were to run into people because they were not expecting it. Each site also has different ecological sensitivity. 
The PNG works to minimize the number of visitors in sensitive areas and utilize the space that is least likely to be harmed. Trails keep people out of nesting areas and away from sensitive plants. Many areas have been maintained as reserves and will not be used by visitors at all. However, there are reports of visitors stepping beyond the trail markers to get a better picture. It is the guide's job to curtail this activity. The PNG strives to accommodate the desires of the visitors in order to maximize their enjoyment. Many trails are designed to allow the visitor to pass as close as possible to the attractions. overall, the environment is in good condition. Human impacts have been small scale so far and many problems have been solved. There is general agreement that the Park has a good system for controlling visitors, but it is underfinanced and understaffed and must keep up with growth (Emory, 1989).

\section{Estimates of Carrying Capacity}

In 1983, a carrying capacity study was done. The physical capacity was determined for each site. Table 4.7 shows a few of the sites, zone, hours allowed for each visit, length of the trail, number of groups per day, and the daily physical capacity.

To calculate the ecological carrying capacity, physical carrying capacity estimates were adjusted to account for environmental, seasonal, geographical, and unforseen factors. The reduction factor accounts for seasonal and 
Table 4.7 Physical Carrying Capacity of Visitor sites

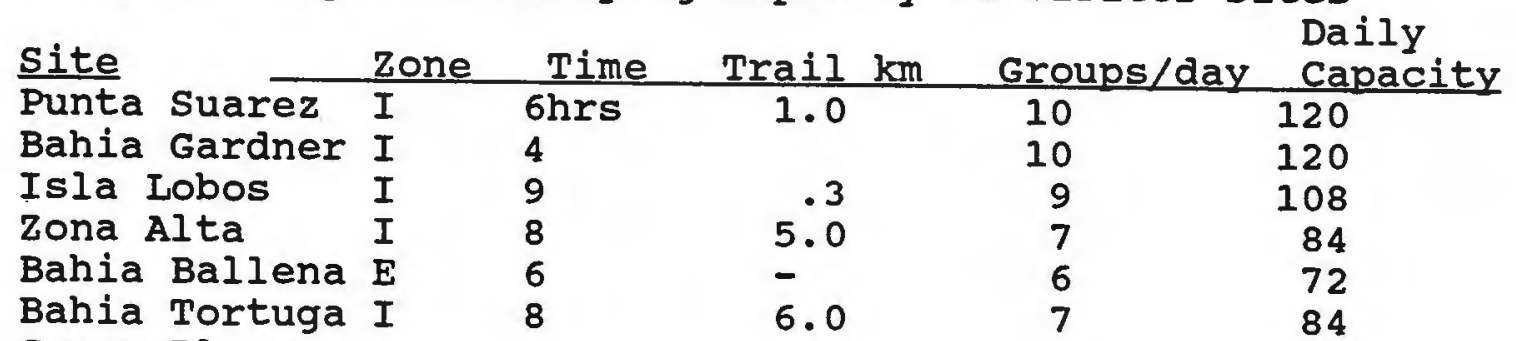

Cerro Playa

(Bartolomé) I

6

.6

12

144

I-Intensive Zone

E-Extensive Zone

Source: Cifuentes, 1984.

ecological characteristics. The following table, Table 4.8 shows the calculations and the effective carrying capacity for some of the sites. Bartolome, the visitor site discussed earlier, has a capacity of 19,699 visitors per year. According to results from 1989, 21,334 visitors were reported to stop in Bartolome. Although each boat has a maximum capacity, and that is the most that is ever reported to the Park Service, it is easy for a captain to take a few extra passengers. In a personal experience, three passengers were hiding in the cabin when the Navy boarded for a routine inspection. These estimates of carrying capacities apparently have already been exceeded, and enforcement is not sufficient.

The facilities carrying capacity is the number of facilities available to accommodate the visitors. The maximum could be determined by adding the capacity of all the boats for every day of the year plus the number of hotel rooms available. If everything were occupied, then the 
Table 4.8 Effective Carrying Capacities

\begin{tabular}{lrrrr} 
& Daily & Total & Daily & Annual \\
\cline { 2 - 5 } Site & Capacity & Reduction & Capacity & Capacity \\
Punta Suarez & 120 & .153 & 18.36 & 6,610 \\
Bahia Gardner & 120 & .153 & 18.36 & 6,610 \\
Isla Lobos & 108 & .153 & 16.52 & 5,947 \\
Zona Alta & 84 & .115 & 9.66 & 3,478 \\
Bahia Ballena & 72 & .228 & 16.42 & 5,911 \\
Bahia Tortuga & 84 & .228 & 19.15 & 6,894 \\
Cerro Playa & & & & \\
$\quad$ (Bartolomé) & 144 & .228 & 54.72 & 19,699
\end{tabular}

Source: Cifuentes, 1984.

maximum facility capacity would be reached. Vacancy rates should be examined to determine how much of this carrying capacity is being used. Currently, there are no accurate records kept, but some estimates indicate that the vacancy rates are quite high, and there are many hotels and boats under construction and waiting for permits from the PNG to begin operations. The facilities carrying capacity does not appear to be in danger of being exceeded, but vacancy rates would be useful in order to determine if the islands have excess capacity.

Understanding social impacts and social carrying capacity is very important in the long run in order to maintain the quality of the visitor experience. If that is allowed to deteriorate, the islands may gain a reputation as a place that is not favorable to visit. Although the Park Service is concerned with the visitor experience, there have been no direct studies to assess the social carrying capacity. The following chapter utilizes selected information from the surveys to describe the tourists and to 
understand the difficulties in determining a social carrying capacity. 
CHAPTER 5

\section{ANALYSIS}

\section{Introduction}

The major objective of this study is to gain a better understanding of social carrying capacity characteristics in the Galápagos Islands. This information will aid managers in planning and utilizing the resources. The following data was collected in two surveys and it has been grouped into the following sections: duration of visits, age of visitors, income levels, importance, accommodations, places of origin, measures of satisfaction, and relation of satisfaction to use levels.

\section{Duration of visits}

The Galápagos Islands are very unique. The results show that visitors usually combine their vacation in the Galápagos with trips to other destinations in South America, such as Quito, Ecuador, and Lima, Peru. The mean length for total vacation was 30.6 days in the 1986 survey. The total number of days ranged from one to 365 . The number of days spent in the Galápagos ranged from one to 60 with a mean of 7.0. The number of sites visited varies with the length of stay. In 1986, the mean number of sites visited was 10.9, with a range from 3 to 30 . The mean number of sites visited per day was 1.6 .

Total vacation days in 1991, including all destinations ranged from 4 to 365 with a mean of 26.5 days. Other places 
in Ecuador are frequently visited. The mean number of days spent in the Galápagos was 7.1 and ranged from 2 to 42 . The mean number of days spent on boats was 4.65 , and the mean number of days spent in hotels was 2.34 .

The average number of days spent in the Galápagos was almost the same for both samples. Most of the visitors purchase a package that is offered for 3, 4, 7, and 10 days.

\section{Age of Visitors}

The Galápagos Islands are frequently visited by older people. It is an expensive, out of the way destination taking time and money. Many of the boats, especially the 90 passenger ships, accommodate the needs of older people. In 1986, the oldest group was 71 to 80 years ( 10.4 percent), the largest age group of respondents was in the range of 61 to 70 years, representing 25.1 percent of the sample. This age group was followed by 51 to 60 years ( 21 percent), 31 to 40 years ( 17.3 percent), 41 to 50 years ( 15.6 percent), 21 to 30 years ( 7.8 percent), and last, 20 years or younger $(2.9$ percent). The median is in the 51 to 60 years age range. Figure 5.1 and Table 5.1 summarize the distribution. Table 5.1 Frequency Distribution, Age 1986

$\begin{array}{lrl}\text { Responses } & \mathrm{n}=347 & \% \\ \text { 1. } 20 \text { Years or less } & 10 & 2.9 \% \\ \text { 2. } 21 \text { to } 30 \text { Years } & 27 & 7.8 \% \\ \text { 3. } 31 \text { to } 40 \text { Years } & 60 & 17.3 \% \\ \text { 4. } 41 \text { to } 50 \text { Years } & 54 & 15.6 \% \\ \text { 5. } 51 \text { to } 60 \text { Years } & 73 & 21.0 \% \\ \text { 6. } 61 \text { to } 70 \text { Years } & 87 & 25.1 \% \\ \text { 7. } 71 \text { to } 80 \text { Years } & 36 & 10.4 \% \\ \text { 8. Older than } 80 & 0 & 0.0 \%\end{array}$

Median: 51 to 60 age range 


\section{AGE \\ 1986}

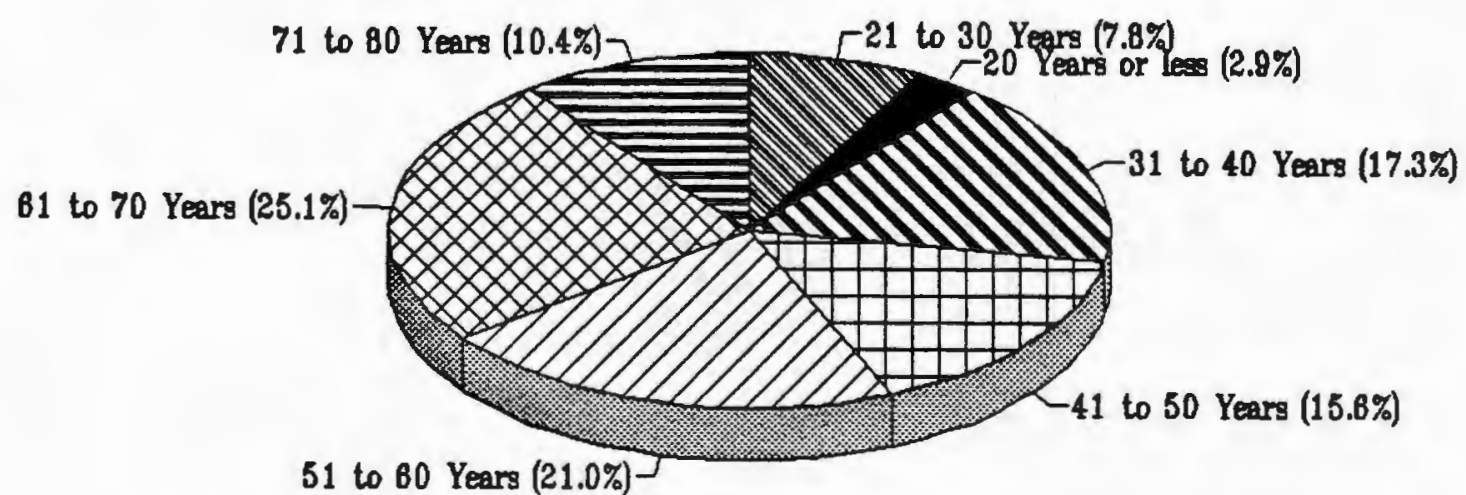

51 to 60 Years $(21.0 \%)$

Figure 5.1 Age. Distibution, 1986

The 1991 survey showed a younger group of visitors. The mean age was 38 with a range of 18 to 78 . This can be explained by the sample surveyed. The large, 90 passenger vessels tend to accommodate older people, and during the time that the 1991 survey was conducted, two of the larger vessels were out of service. The result is a larger proportion of younger people. The ages were broken down into the same age groups as in the 1986 Woods Hole Survey. 
Figure 5.2 and Table 5.2 show the distributions.

Table 5.2 Frequency Distribution, Age 1991

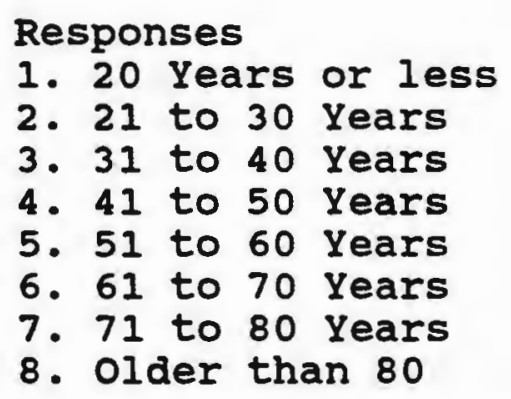

\begin{tabular}{ll}
$n=369$ & \multicolumn{1}{c}{$\%$} \\
11 & $3.0 \%$ \\
112 & 30.48 \\
100 & $27.1 \%$ \\
82 & 22.28 \\
39 & 10.68 \\
20 & 5.48 \\
5 & 1.48 \\
0 & 0.08
\end{tabular}

Median: 31 to 40 age range

\section{AGE \\ 1991}

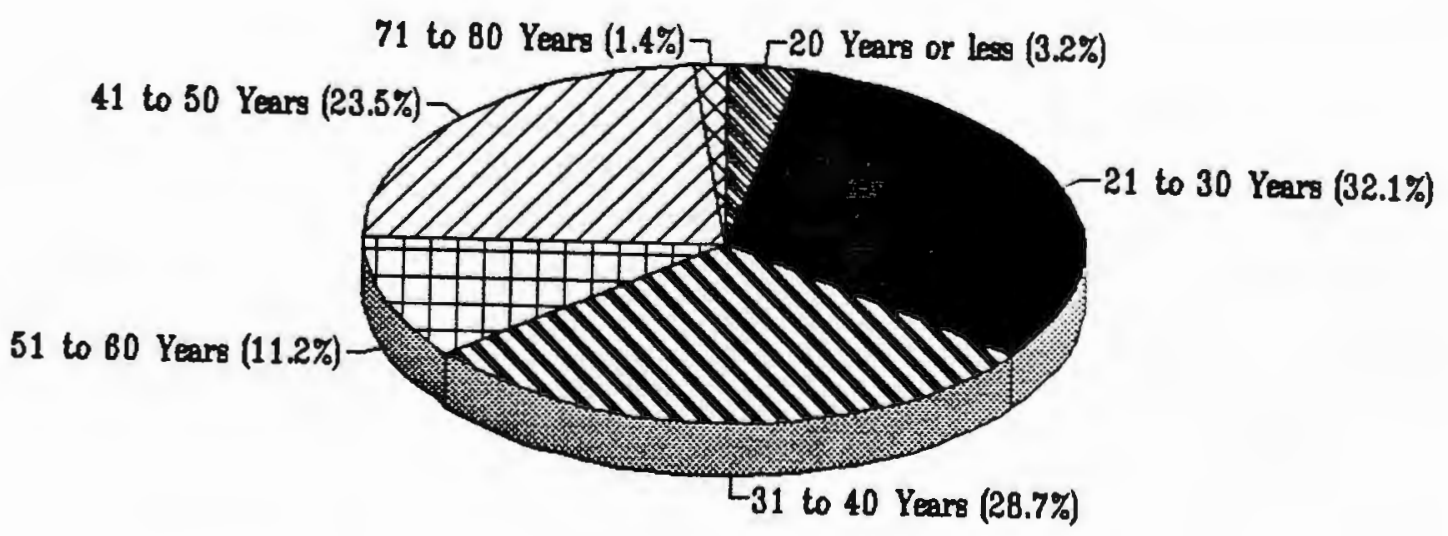

Figure 5.2 Age Distribution, 1991 


\section{Income Levels}

The Galápagos Islands are a relatively expensive place to visit. Income levels of visitors reflect this. In 1986, the median income level was in the $\$ 50,000$ to $\$ 99,999$ range. Thirty percent of the respondents had family incomes in excess of $\$ 100,000$. The second largest group was in the $\$ 50,000$ to $\$ 99,999$ range (26.1 percent), $\$ 25,000$ to $\$ 49,999$ was the third largest (24.7 percent), $\$ 10,000$ to $\$ 24,999$ (12.7 percent), $\$ 5,000$ to $\$ 9,999$ (4.8 percent), and last, less than $\$ 5,000$ ( 1.4 percent). Figure 5.3 and Table 5.3 summarize the results.

Table 5.3 Frequency Distribution, Income 1986

$\begin{array}{lcl}\text { Responses } n=290 & \% \\ \text { 1. } \$ 5,000 & 4 & 1.4 \% \\ \text { 2. } \$ 5,000 \text { to } \$ 9,999 & 14 & 4.8 \% \\ \text { 3. } \$ 10,000 \text { to } \$ 24,999 & 37 & 12.8 \% \\ \text { 4. } \$ 25,000 \text { to } \$ 49,999 & 72 & 24.8 \% \\ \text { 5. } \$ 50,000 \text { to } \$ 99,999 & 76 & 26.2 \% \\ 6 \text { 6. } \$ 100,000 \text { or more } & 87 & 30.0 \%\end{array}$

Median: $\$ 50,000$ to $\$ 99,999$ range

Mean Response 4.6: $\$ 50,000$ to $\$ 99,999$ range 


\section{INCOME \\ 1986}

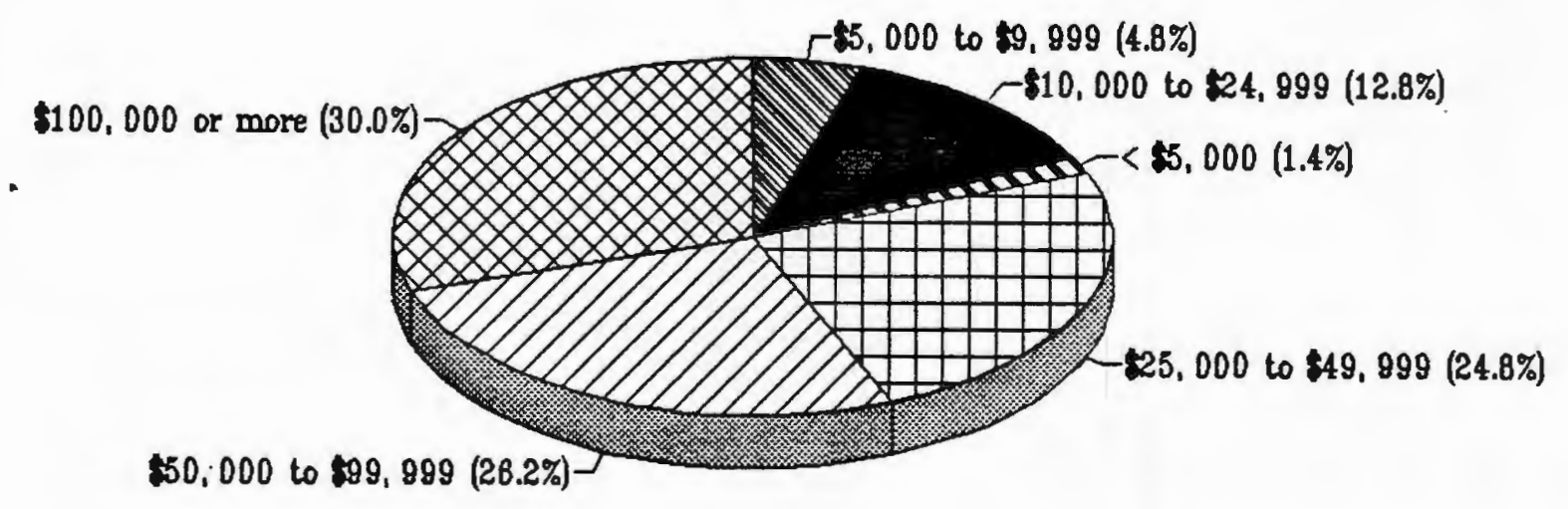

Figure 5.3 Distribution of Income, 1986

The younger age group in 1991 is also reflected in the results for income levels. Average family income was $\$ 49,583.60$. There is a smaller proportion in the high income range of $\$ 100,000$ or more, 13.2 percent. The responses were also divided into the same categories as in the 1986 woods Hole survey. The median income was in the $\$ 25,000$ to $\$ 49,999$ range. Figure 5.4 and Table 5.4 show the results. 
Table 5.4 Frequency Distribution, Income 1991

$\begin{array}{lrl}\text { Responses } & \mathrm{n}=243 & \text { \% } \\ \text { 1. } \$ 5,000 & 37 & 15.2 \% \\ \text { 2. } \$ 5,000 \text { to } \$ 9,999 & 11 & 4.5 \% \\ \text { 3. } \$ 10,000 \text { to } \$ 24,999 & 48 & 19.8 \% \\ \text { 4. } \$ 25,000 \text { to } \$ 49,999 & 57 & 23.5 \% \\ \text { 5. } \$ 50,000 \text { to } \$ 99,999 & 58 & 23.9 \% \\ \text { 6. } \$ 100,000 \text { or more } & 32 & 13.2 \%\end{array}$

Median: $\$ 25,000$ to $\$ 49,999$ range

INCOME

1991

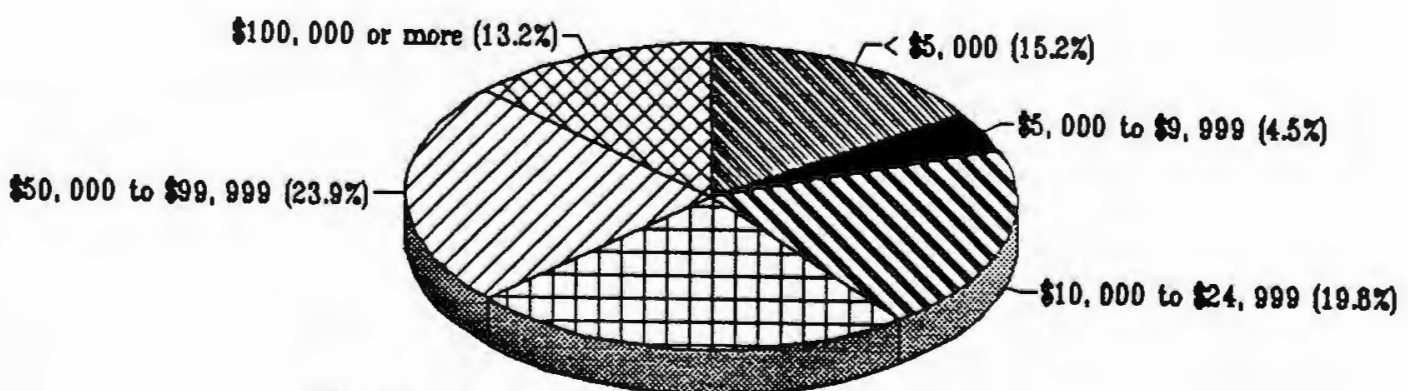

25,000 to $449,899(23.5 \%)-$

Figure 5.4 Distibution of Income, 1991 


\section{Importance}

The Galápagos Islands are very important. Regardless of other destinations, the islands are the main focus for most trips. For the 1986 survey, when asked how important the Galápagos was compared to other destinations on their vacations, 39.7 percent said it was essential, 35.1 percent said it was most important, 15.7 percent said it was about equal to other destinations, 1.1 percent said it was least important, and it was not relevant to 8.3 percent since they were visiting the Galápagos only. Table 5.5 lists the results.

Table 5.51986 Importance

Responses

Essential

Most Important

Equal to Other Destinations

Least Important

Does Not Apply $\mathrm{n}=350$

139

123

55

4

29
8

$39.7 \%$

$35.1 \%$

$15.7 \%$

$1.1 \%$

$8.3 \%$

There are very few substitutes for a Galápagos vacation since the islands are so unique. In 1986, when asked what they would have done if they did not go to the Galápagos, twenty-nine percent said they would have worked, an additional 16.1 percent said they would have stayed at home, and 5.6 percent were not sure. The remaining 49.3 percent would have gone elsewhere on vacation.

In 1991, the survey asked the respondents to rank the importance of the Galapagos in relation to other places visited on a scale of -2 to +2 . It was ranked most 
important +2 by 77.7 percent. It was ranked +1 by 20.2 percent. Only 1.7 percent and .3 percent ranked the Galápagos 0 and -1 respectively. The Galápagos Islands are also very important for tourism in the rest of Ecuador. When asked what they would do if they could not visit the Galápagos, 29.9 percent said that they would have travelled to another country, 16.8 percent of the visitors said that they would have stayed at home, and 1.9 percent said that they would have spent less time in Ecuador. Some felt that they would take the trip at a later date (4.7 percent), others were not sure what they would do $(7.2$ percent). A large percentage (39.6 percent) said that they would have travelled elsewhere within Ecuador. This demonstrates the important role that Galápagos plays in encouraging and increasing tourism in the rest of the country.

In both surveys, the importance of the Galapagos Islands compared to other destinations was very high. In 1986, the categories Essential and Most Important were 74.8 percent, and in 1991, 77.7 percent ranked the Galápagos as the most important. The Galápagos Islands are the main reason many visitors go to Ecuador, and while they are there, they visit other places. The islands are very important to tourism in Ecuador and other parts of South America.

\section{Accommodations}

Possible accommodations in the islands include hotels, but most visitors stay on boats. In the 1986 survey, 7.1 
percent stayed on a sailboat, 31.1 percent on a boat with fewer than 25 passengers, and 61.9 percent on a boat with 25 to 100 passengers. None of the respondents reported staying in hotels while in the islands.

\section{Places of Origin}

The survey was conduated during the months of January, February, and March, during which the average percentage of national visitors was 26.5 percent. In this sample, 90.6 were foreign, and only 9.4 percent were from Ecuador. This survey did not include visitors who stayed in hotels. It is less expensive to stay in a hotel and take day boats to the visitor sites, and it is easier for a national to make the arrangements than it is for a foreigner to do so. Until March 13, 1992, the Galápagos Islands were connected by only one phone line to mainland Ecuador. Radios were also used for communication. All travel arrangements went through these channels, severely limiting the ability to make hotel arrangements. Information obtained by the park service shows a breakdown of national and international visitors by month. See Table 5.6.

Visitors come from all over the world to see the unique flora and fauna of the Galápagos Islands. Many Ecuador nationals take advantage of the proximity and reduced prices they receive when visiting the islands. A large proportion of the visitors from the 1986 study were from the United states (68.1 percent). The other countries were Ecuador (9.4 percent), Canada (5 percent), Switzerland (4.4 
Table 5.6 Average Number of National and International Visitors by month, 1979-1986.

$\begin{array}{llrlll}\text { Month } & \text { Avg Nat'I Avg Int'l Total } & \begin{array}{l}\text { Nat'l } \\ \text { Of Total }\end{array} & \begin{array}{l}\text { Int'l } \% \\ \text { Of Total }\end{array} \\ \text { January } & 319.25 & 1,424.38 & 1,743.63 & 18.31 \% & 81.69 \% \\ \text { February } & 394.63 & 952.00 & 1,346.63 & 29.31 \% & 70.69 \% \\ \text { March } & 476.75 & 1,022.63 & 1,499.38 & 31.80 \% & 68.20 \% \\ \text { April } & 645.25 & 995.88 & 1,641.13 & 39.32 \% & 60.68 \% \\ \text { May } & 589.38 & 820.25 & 1,409.63 & 41.81 \% & 58.19 \% \\ \text { June } & 481.25 & 788.75 & 1,270.00 & 37.89 \% & 62.11 \% \\ \text { July } & 462.50 & 1,098.88 & 1,561.38 & 29.62 \% & 70.38 \% \\ \text { August } & 761.63 & 1,259.25 & 2,020.88 & 37.69 \% & 62.31 \% \\ \text { September } & 778.38 & 630.00 & 1,408.38 & 55.27 \% & 44.73 \% \\ \text { October } & 525.13 & 854.13 & 1,379.26 & 38.07 \% & 61.93 \% \\ \text { November } & 387.13 & 972.75 & 1,359.88 & 28.47 \% & 71.53 \% \\ \text { December } & 378.13 & 858.63 & 1,236.76 & 30.57 \% & 69.43 \%\end{array}$

Total 6,199.41 11,677.53

Source: Boo, 1990b

percent), all other European countries ( 9.4 percent), countries in South America (2.5 percent). The Middle East, Japan, Kenya, and Central America were last (.3 percent each). Figure 5.5 and Table 5.7 show the distribution. Table 5.7 Country Distribution 1986

$\begin{array}{lll} & \text { Number of People } & \% \\ \text { Argentina } & 2 & 0.6 \% \\ \text { Austria } & 4 & 1.1 \% \\ \text { Brazil } & 1 & 0.3 \% \\ \text { Canada } & 18 & 5.0 \% \\ \text { Colombia } & 2 & 0.6 \% \\ \text { Denmark } & 1 & 0.3 \% \\ \text { Ecuador } & 34 & 9.4 \% \\ \text { England } & 8 & 2.2 \% \\ \text { Finland } & 2 & 0.6 \% \\ \text { France } & 2 & 0.6 \% \\ \text { Germany } & 6 & 1.7 \% \\ \text { Holland } & 3 & 0.8 \% \\ \text { Israel } & 1 & 0.3 \% \\ \text { Italy } & 3 & 0.8 \% \\ \text { Japan } & 1 & 0.3 \% \\ \text { Kenya } & 1 & 0.3 \% \\ \text { Mexico } & 1 & 0.3 \% \\ \text { Peru } & 4 & 1.1 \% \\ \text { Sweden } & 5 & 1.4 \% \\ \text { Switzerland } & 16 & 4.4 \% \\ \text { USA } & 245 & 68.1 \%\end{array}$




\section{Country Distribution 1986}

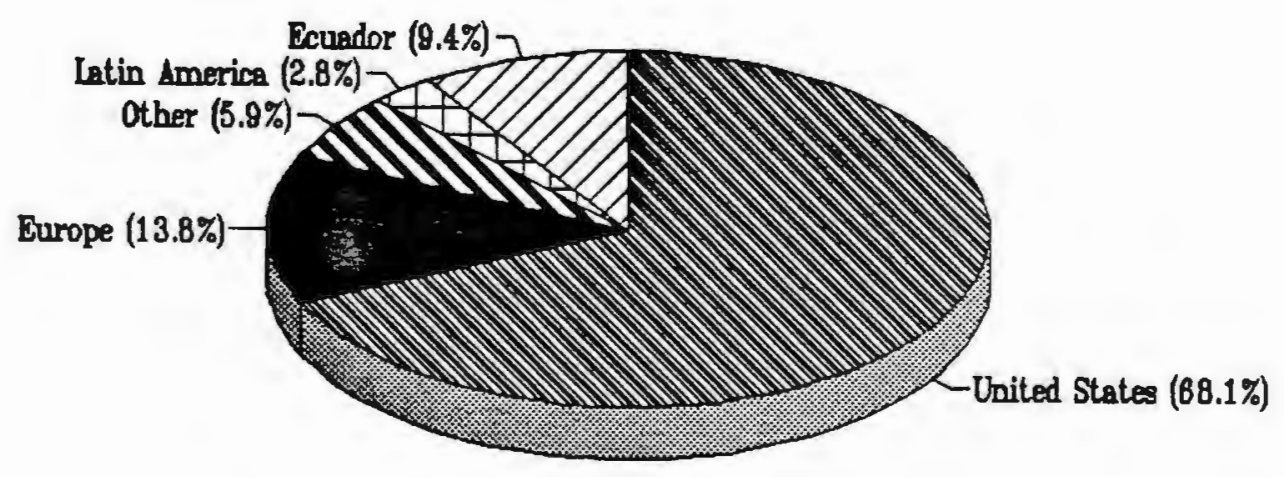

Figure 5.5 Country Distribution, 1986

In 1991, international visitors made up 74.9 percent of the sample. National visitors made up 25.1 percent. The United states made up the largest group with 25.9 percent of the visitors, Ecuador was second with 25.1 percent, followed by England, 9.9 percent, Germany, 9.6 percent, France, 9.4 percent, all other European countries, 13.7 percent. There were a few visitors from Japan ( 1.6 percent), the Middle East ( 1.1 percent), Africa (.6 percent), Canada ( 1.6 
percent), and South America and the Caribbean ( 1.6 percent). Figure 5.6 and Table 5.8 show all the countries and the distribution.

Table 5.8 Country Distribution 1991

$\begin{array}{lcc} & \text { Number of People } & \% \\ \text { Germany } & 36 & 9.5 \% \\ \text { Argentina } & 1 & 0.3 \% \\ \text { Australia } & 4 & 1.1 \% \\ \text { Austria } & 9 & 2.4 \% \\ \text { Belgium } & 3 & 0.8 \% \\ \text { Canada } & 6 & 1.6 \% \\ \text { China } & 1 & 0.3 \% \\ \text { Colombia } & 2 & 0.5 \% \\ \text { Denmark } & 1 & 0.3 \% \\ \text { Ecuador } & 94 & 24.9 \% \\ \text { Spain } & 7 & 1.9 \% \\ \text { France } & 35 & 9.3 \% \\ \text { French Guiana } & 1 & 0.3 \% \\ \text { Netherlands } & 13 & 3.4 \% \\ \text { England } & 37 & 9.8 \% \\ \text { Israel } & 4 & 1.1 \% \\ \text { Italy } & 5 & 1.3 \% \\ \text { Japan } & 6 & 1.6 \% \\ \text { Lesser Antilles } & 2 & 0.5 \% \\ \text { South Africa } & 1 & 0.3 \% \\ \text { Switzerland } & 8 & 2.1 \% \\ \text { Sweden } & 5 & 1.3 \% \\ \text { United States } & 97 & 25.7 \%\end{array}$

Places of origin fluctuate from year to year for many reasons. Changes in exchange rates and the strength or weakness of the U.S. dollar may affect the number of visitors from the United States. The Persian Gulf war in 1991 may also have discouraged many would be travelers from world travel. 


\section{Country Distribution 1991}

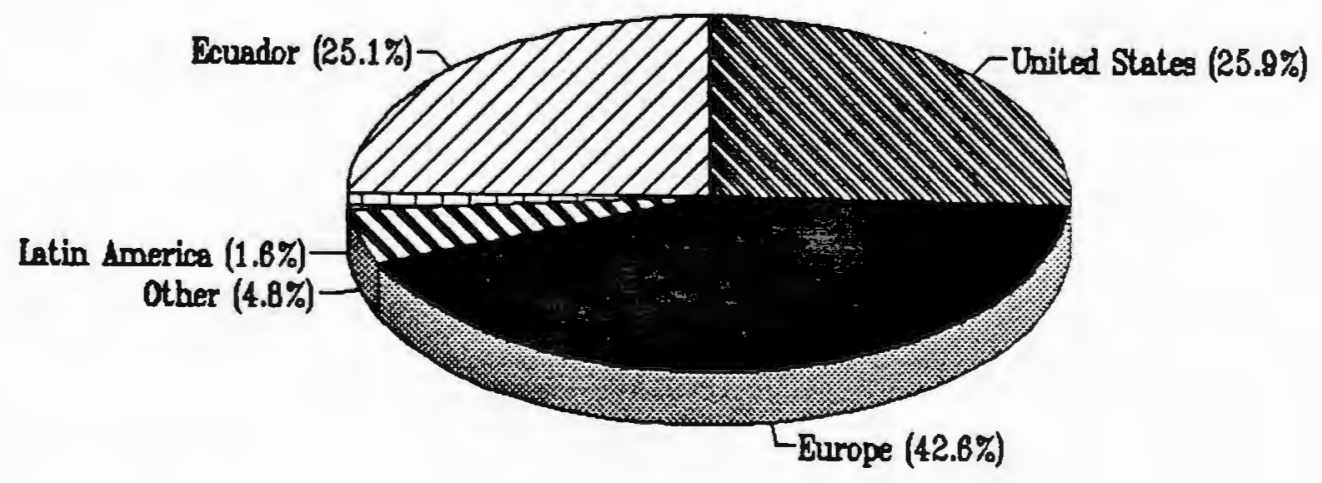

Figure 5.6 Country Distribution, 1991

Measures of Satisfaction

The 1986 survey asked visitors if they saw all the types of wildife they hoped to see. A little more than one half responded yes. Although they did not see all the wildlife they wanted to see, they still enjoyed their trips. When asked if they would still go to the Galapagos knowing what they knew about the islands and the vacation, 96.5 percent said they would still go and only 3.5 percent said 
they would not.

All visitors must pay the park fee upon arrival in the islands. Only 9.5 percent felt that the trip was not worth the fee, and they were all people who did not see all the wildlife that they had hoped to see. The remaining 90.5 percent felt that it was worth it. Table 5.9 summarizes the results for 1986 .

Table $5.9 \quad 1986$ summary of Satisfaction

Saw all wildlife

$\begin{array}{ccrl}\text { Yes } & 54.9 \% & 185 & \\ \text { No } & 45.1 \% & 152 & \mathrm{n}=337 \\ \text { Still go to Galápagos } & & \\ \text { Yes } & 96.5 \% & 335 & \\ \text { No } & 3.5 \% & 12 & \mathrm{n}=347 \\ \text { Worth the Fee } & & & \\ \text { Yes } & 90.5 \% & 295 & \\ \text { No } & 9.5 \% & 31 & \mathrm{n}=326\end{array}$

Visitors to the Galápagos Islands are usually quite satisfied with their experience. Satisfaction with nature was ranked highly by respondents in 1991. On a scale of 1 to $3,89.9$ percent gave a 3,9 percent gave a 2 , and only 1.1 percent gave a 1 . Satisfaction with services was mixed. Fifty-six percent ranked services at $3,34.1$ percent ranked it at 2 , and 9.9 percent gave it a 1 .

The survey asked for suggestions for improvements. Better basic services such as landing sites, transportation, water, and electricity were suggested by 20.2 percent of those who responded to the question. Another 20.2 percent suggested better organization and personal services. The park service should keep these suggestions in mind when 
formulating changes. Table 5.10 summarizes the results for 1991.

Table $5.10 \quad 1991$ Summary of Satisfaction

Satisfaction with Nature

$+3$

$+2$

$89.9 \%$

318

$+1$

$9.0 \%$

$1.1 \%$

32

$4 n=354$

Satisfaction with Services

$+3$

$+2$

$56.0 \%$

$34.1 \%$

$+1$

$9.9 \%$

192

117

$34 n=343$

Suggested Improvements

$\begin{array}{lrrr}\text { All was fine } & 8.9 \% & 19 & \\ \text { More comfortable boat } & 8.9 \% & 19 & \\ \text { Prolong my stay } & 7.5 \% & 16 & \\ \text { Provide more bus tours } & 1.9 \% & 4 & \\ \text { Provide more information } 11.3 \% & 24 & \\ \text { Better basic services } & 20.2 \% & 43 & \\ \text { Better organization } & 20.2 \% & 43 & \\ \text { Prices too high } & 2.8 \% & 6 & \\ \text { More control, less tourism } 8.0 \% & 17 & \\ \text { Travel agent problems } 10.3 \% & 22 & \mathrm{n}=213\end{array}$

Initially, it was hoped that comparisons could be made between the results from 1986 and 1991. Due to differences in the surveys, unqualified comparisons would be inappropriate for several reasons. First, the surveys were conducted at different times of the year. In 1986, the surveys took place during January, February, and March, and in 1991, it was during July, August, and september. As mentioned earlier, percentage of foreign visitors varies throughout the year; there is a peak of foreign visitors in January, February, and March, and a peak for nationals in september. The 1986 survey did not include any visitors who stayed in hotels, and many of the respondents in 1986 were 
passengers on the Santa Cruz, a 90 passenger vessel. During the survey in 1991, the santa cruz was undergoing repairs, and another 90 passenger vessel, the Bucanero, left the Galápagos in 1990 .

\section{Use Levels and Measures of Satisfaction}

Measures of satisfaction with groups encountered is on an ordinal scale in this study. Ordinal data on attitudes are frequently treated as interval data in published research in the major sociological and psychological journals (Heberlein and Shelby, 1977). The use of interval techniques on ordinal measures does not seriously violate any assumptions. Labovitz (1967) cites four arguments for using interval techniques with ordinal data. First, ordinal and other non-parametric techniques are insensitive. second, only a small error results from assigning numbers to ordinal data and treating them as an interval scale. Third, parametric tests show robustness, which is the ability of a statistical test to maintain its logically deduced conclusion when one or more assumptions (like normality) have been violated. And finally, the power-efficiency of parametric tests are greater. Also, Borgatta (1968:29) states "that for correlation and regression analysis, assumptions of normality and continuous distributions are not necessary." The researcher is the one who should determine his choice of a statistic.

other appropriate techniques were used but the results were so poor that a sophisticated analysis was not 
warranted. The chi-square statistic was one approach, but was insufficient in providing useful results because there were too many empty data cells. The author felt that the Pearson product correlation coefficient should be used.

In the application of this social carrying capacity study, measures of satisfaction must be related to different use levels in order to understand the social impacts at different use levels. In 1986, there was a measure of maximum willingness to pay, satisfaction with the size of tour groups, and satisfaction with regards to encounters with other groups at the visitor sites. In 1991, there was a measure of satisfaction in relation to number of groups encountered. The following analysis examines these relationships in the Galapagos Islands based on the theoretical framework presented in Chapter 3.

\section{Results}

The question about maximum willingness to pay for park access was designed to measure satisfaction with experience. All responses were converted to U.S. dollars. International and national responses were separated because international visitors paid $\$ 30$ and nationals only paid about $\$ 6$. The mean international response was $\$ 79.75$. The standard deviation was 119.65. This indicates that there was a very wide variation in people's responses. The national response mean was $\$ 22.32$. The standard deviation was 23.5. Table 5.11 shows the results. 
Table 5.11 Willingness to Pay

Mean

Range

$n$

Standard Deviation
International National

$\$ 79.75$

$0-\$ 1,000$

233

119.65
$\$ 22.32$

$0-\$ 100$

25

23.5

To understand the relationship better, the mean willingness to pay was calculated at each number of groups encountered. The relationship shows that as number of groups encountered increases, willingness to pay generally decreases which supports our assumption. Table 5.12 and Figure 5.7 show the results.

Table 5.12 WTP by Number of Groups

Foreign

$\begin{array}{llrr}\text { Number of Groups } & \text { Mean WTP } & \text { Std Dev } & \text { n } \\ 1 & \$ 106.72 & 161.71 & 44 \\ 2 & \$ 108.09 & 181.92 & 46 \\ 3 & \$ 64.35 & 64.48 & 73 \\ 4 & \$ 74.14 & 96.21 & 29 \\ 5 & \$ 49.29 & 23.53 & 7 \\ 6 & \$ 60.00 & 27.08 & 4 \\ 7 & \$ 50.00 & - & 1 \\ 8 & \$ 62.50 & 48.87 & 4 \\ 10 & \$ 35.00 & 21.21 & 2\end{array}$

National

$\begin{array}{lccc}\text { Number of Groups } & \text { Mean WTP } & \text { Std Dev } & \text { n } \\ 1 & \$- & - & 0 \\ 2 & \$- & - & 0 \\ 3 & \$ 20.57 & 21.10 & 7 \\ 4 & \$ 13.00 & 10.31 & 6 \\ 5 & \$ 35.00 & 7.07 & 2 \\ 6 & \$- & - & 0 \\ 7 & \$- & - & 0 \\ 8 & \$ 28.50 & 30.40 & 2 \\ 10 & \$ 13.00 & - & 1\end{array}$




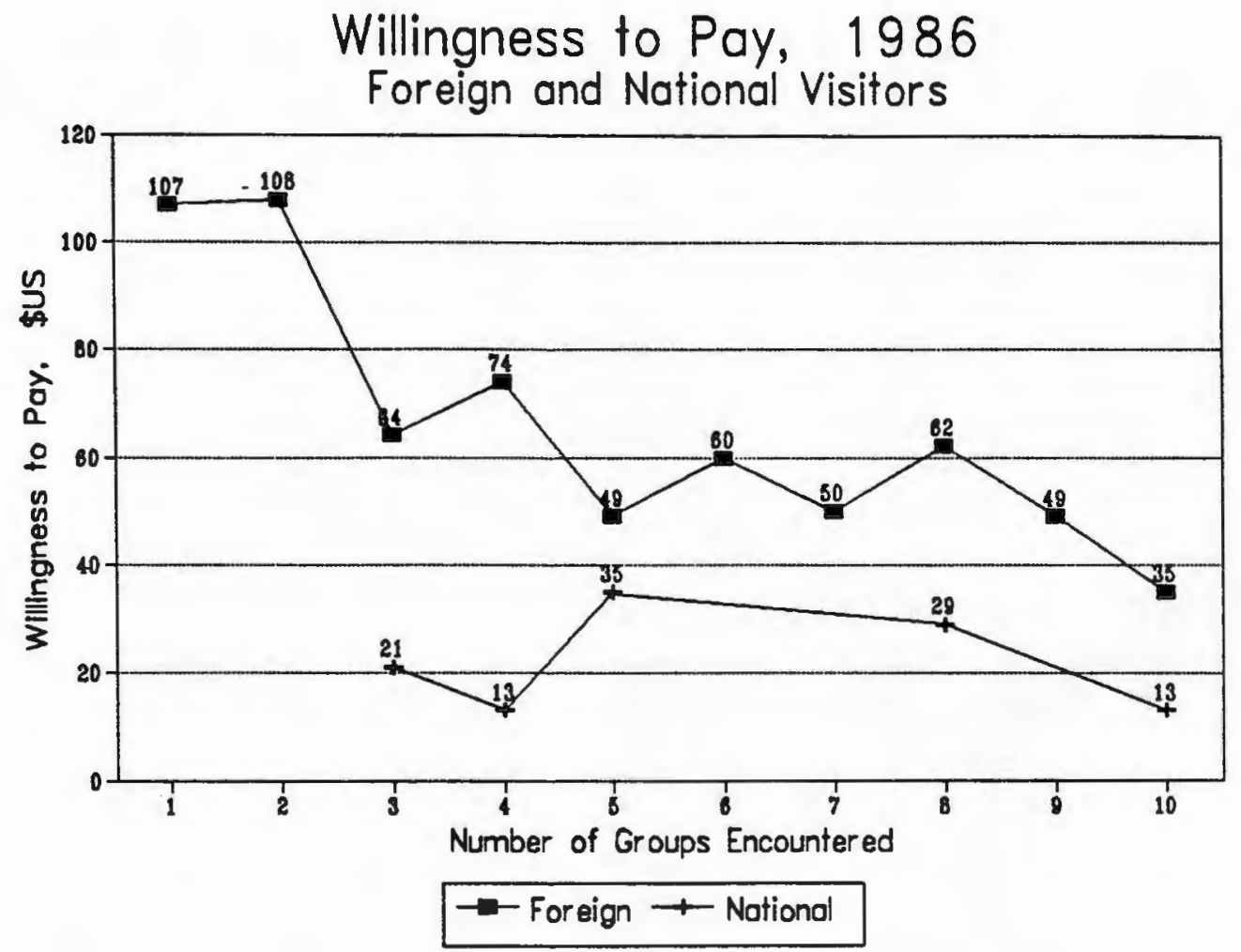

Figure 5.7 Willingness to Pay, 1986

A requirement of this approach is to have a relationship between number of groups encountered and satisfaction. Low numbers of groups encountered should be reflected in a high willingness to pay value. As was expected, the correlation was negative. It was -.16 with $p$ $=.0159$. Although it is statistically significant, it explains only $2.5 \%$ of the variance therefore should not be used to determine social carrying capacity. 
There are problems with the willingness to pay approach as a measure of satisfaction. People may understate their willingness to pay because if it was discovered that people were willing to pay more, then they might actually have to pay more at some time in the future. Also, individuals may not respond the same in a hypothetical situation as they would in a real situation. The act of paying money is very different from saying that you will pay money. The ability to pay may also affect willingness to pay. An individual may place a high value on solitude at a visitor site but is unable to pay because of a low income. The willingness to pay value would be understated again. Respondents' conceptual understanding of the willingness to pay measure is sometimes low. Some people indicated that they were willing to pay $\$ 0$ yet they paid $\$ 30$ at the time, and felt that the trip was worth the fee.

There is a correlation of .21 between willingness to pay and income, and a correlation of -.16 between willingness to pay and number of groups encountered. When income is controlled, this correlation only drops to -.15. See appendix 3 for calculation. These results show that as number of groups encountered increases, willingness to pay and satisfaction decreases despite level of income; however, it only explains $2.25 \%$ of the variance.

The correlation between satisfaction and size of tour group was $-.13, \mathrm{p}=.0174, \mathrm{n}=337$. Satisfaction decreases as the size of tour groups increase but the correlation was low, explaining only $1.69 \%$ of the variance. It seems 
reasonable to state that in general, a larger group is less satisfactory than a smaller one but an optimal size of a tour group would depend on the preferences of the individual. Many of these variables were recalculated separating groups by age, income, and length of stay, without significant changes in relationships.

The most important measure of satisfaction in this carrying capacity study is the impact on enjoyment of the number of groups encountered. This correlation was also very low at $.02, p=.6581, n=300$. It was not statistically significant. The coefficient of determination is .0004 . only about .04 percent of the variation can be explained by this relationship. In past studies, similar to this one, low correlations were also found between key variables. Group satisfaction and number of sites visited have a correlation coefficient of -.21 . As a visitor spends more time in the Galápagos and visits more sites, the interaction with higher numbers of groups has more of a negative effect on enjoyment. Age and group satisfaction has a correlation coefficient of .31 . The coefficient of determination is .096. Older people are more likely to have a positive response to encounters with large numbers of other groups.

Table 5.13 lists the correlations and probabilities for the statistically significant relationships and those that are the focus of the study. Although some correlations are statistically significant, it is the viewpoint of the author that there is no practical significance to the values because they are too low. For example, since the 
coefficient of determination for willingness to pay and number of groups encountered is only .025, this relationship only explains about $2.5 \%$ of the variance. It does not provide anywhere near a complete understanding of the relationship. Decision making should not be made on such inadequate information.

Table 5.13 1986 Correlations

WTP Pearson $r \quad \mathrm{p} n$

Income \# of Groups

0.21

$-0.16$

0.0017

217

Group sat

Days Galáp

Sites

Age

Groups

WTP

Wildlife

$-0.25$

$-0.21$

0.31

0.02

0.0159

229

Tour sat

Toursize
Groups
Group Sat

Toursize
Groups
Group Sat

Toursize
Groups
Group Sat

$-0.05$

$-0.13$

0.0001

0.0002

335

0.0001

0.6581

0.4033

326

300

0.0252

249

319

-0.13
-0.10
0.15

0.0174

337

0.0903

0.0072

324

\section{Results}

The following table (Table 5.14), shows the statistically significant relationships between the variables in 1991. The correlation between number of groups and group satisfaction is higher for this sample than the previous sample. It is .13 with $\mathrm{p}=.0546, \mathrm{n}=207$. In this sample, as number of groups increase, satisfaction also increases. 
Nature sat

\begin{tabular}{lcl}
\multicolumn{3}{c}{ Pearson } \\
& $\mathrm{p}$ & $\mathrm{n}$ \\
& & \\
0.24 & 0.0001 & 343 \\
0.12 & 0.0748 & 212
\end{tabular}

Service sat

Groups

0.12

0.0748

212

Service sat

cost per day

0.16

0.0169

219

Fam Income

0.19

0.0038

226

Age

Total Days

Groups

0.25

0.0001

338

$-0.14$

0.0092

333

$-0.10$

0.1552

204

Group sat

Package cost

$-0.34$

0.0001

211

Cost per day

$-0.29$

0.0001

220

Fam Inc

$-0.17$

0.0134

221

Groups

0.13

0.0546

207

Visit Before

Groups

Importance

Package cost

0.36

0.0314

36

0.38

0.002

62

$-0.41$

0.0052

44

Package cost

Age

0.28

0.0001

229

Income

0.44

0.0001

156

Boat Capacity

Importance

Age

0.18

0.0044

255

Income

0.22

0.0002

271

0.19

0.0082

186

Importance

Age

0.19

0.0004

339

Groups

Toursize

0.73

0.0623

7

There were, however, some interesting relationships. Satisfaction with nature and satisfaction with services has a correlation coefficient of .24 and is statistically significant at $p<.01$ which explains 5.8 percent of the variance.

The correlation between group satisfaction and groups 
was recalculated within age groups. The correlation was .27 $(p=.0022, n=125)$ for ages up to 40 , and for 41 years and older, the correlation was negative and low and insignificant at $-.13(p=.2379, n=121)$. In this sample, number of groups encountered is a better measure for younger age groups than older age groups. Further, the younger age groups experienced an increase in satisfaction with higher levels of encounters while older age groups experienced a decrease. This disagrees with the results in 1986 that indicated that older people are more likely to have a positive response as number of groups increases.

The highest correlations were found with the responses by people who had visited the Galápagos Islands before indicating that they may be more sensitive to use levels and their surroundings. Those who had visited before reported encountering more groups. The correlation between visited before and number of groups was .36, $\mathrm{p}=.0314, \mathrm{n}=36$. The correlation between importance of the Galápagos compared to other destinations and visited before was $.38, p=.0020$, $n=62$. If someone has visited the Galapagos before, they are more likely to rank it higher in importance. If someone has visited before, their package cost is likely going to be less possibly because they know how and where to get a lower price. Correlation between visited before and package cost was $-.41, \mathrm{p}=.0052, \mathrm{n}=44$.

Conclusion

Since the correlations for the data were low, the 
results should not be applied to decision making recommendations. The methodology requires a strong relationship between use levels and some measure of social impacts such as satisfaction with number of groups encountered. This does not exist. Any results derived from the data would be questionable and would be difficult to apply in decision making.

At the current level of encounters, this measurement of satisfaction increases as encounters increase. Use levels have not been high enough to show a negative effect on satisfaction. The results of the study do not indicate strong enough relationships to determine what are the current social impacts at the visitor sites. The following graph, figure 5.8, shows the average response at each number of reported groups.

A problem with this methodology is that ordinal responses are difficult to analyze because the measurement of enjoyment is not continuous. The value difference between 'bothered me greatly' and 'bothered me somewhat' is not the same as the difference between 'added to my enjoyment' and 'did not bother me at all', or 'did not bother me at all' and 'bothered me somewhat'.

In many of the visitor sites, visitors expect to see other groups, but the number of groups that they expect may vary. A visitor on the Galápagos Explorer, a 90 passenger cruise vessel, may expect to see four or five other groups from their own boat. A visitor from a four passenger boat may not expect to see many other groups. Because of these 


\section{1}

Group Encounters and Satisfaction

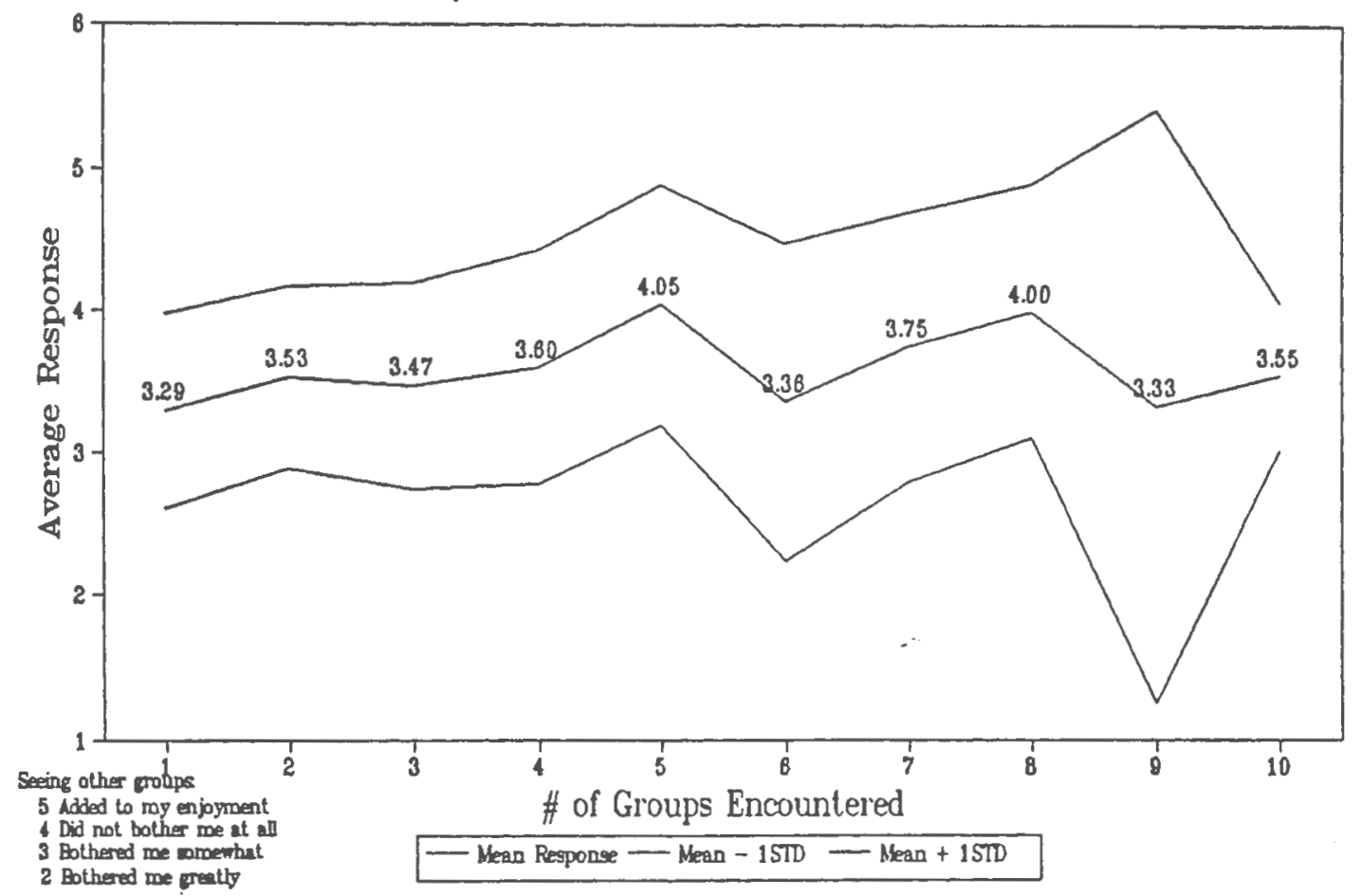

Figure 5.8 Average Response to Groups Encountered

differences in expectations, tour size should be statistically controlled.

The approach that relies on the effect of groups encountered as the sole determinant for social carrying capacity cannot be used. The correlation between the two variables for this survey was positive and low. It could be argued that the data from this survey falls in the range where enjoyment is still increasing. The low correlation 
can be explained by the fact that many things may affect enjoyment. The actual presence of other groups may not be bothersome, but certain types of activities may reduce enjoyment. For some people, the presence or absence of other groups may have no direct impact, but evidence of past visits by other groups, such as litter, footprints, or path erosion, may have an effect on enjoyment. Other methods for viewing social carrying capacity issues should be utilized. 


\section{CHAPTER 6}

\section{DISCUSSION}

\section{Summary}

Social carrying capacity is very important to the long term survival of a tourist destination. The determination of a range of social carrying capacity values, however, is very difficult. Visitors are all very different. A carrying capacity study that only looks at use levels and satisfaction cannot be applied in the Galápagos Islands. Monitoring individual visitor sites at the current use levels, and making the necessary adjustments as problems arise would be more appropriate.

This study does not meet the three basic conditions identified by Shelby and Heberlein (1986) in chapter 3 that are necessary for calculating social capacity based on use levels and satisfaction. There is no known relationship between use levels and social impacts, and this study shows how difficult it is to establish it. There is no agreement among relevant groups about the type of experience to be provided, for example, the Park Service, tour operators, scientists, tour guides, and tourists all desire something a little different. And finally, there is no agreement among relevant groups about appropriate levels of social impacts because there is no easy way to measure the impacts.

Shelby and Heberlein (1986) pointed out that a carrying capacity is related to specific management objectives and a range of acceptable impacts, not a single value. In the 
Galápagos, social impacts cannot be measured by looking at satisfaction and use levels; however, specific management objectives can be developed without this. Some objectives in the Galápagos could be: to provide guides who are able to communicate effectively; to minimize human impacts on animals at visitor sites; and to train guides to stop visitors from petting and feeding the animals. Establishing objectives requires agreement on the type of experience to be provided which should be the first step.

Bury (1976) is concerned that a social carrying capacity study, if based on data that is inaccurate, could be misleading and could distort the potential value of an area. If data from these surveys were used to establish a range for social carrying capacity, the range could greatly over or underestimate the potentials. Overestimating would allow overuse of an area, damaging the physical environment and ecological integrity, and/or, reducing the amount of enjoyment experienced by the visitors. Underestimating the capacity would allow an area to go under utilized, enjoyment that could be achieved would be lost, and economic opportunities would not be put to use.

The four types of carrying capacity, although easier to conceptualize individually, cannot be viewed separately. This study showed how social carrying capacity is related to the other three types. Satisfaction may be diminished if there is environmental degradation, and perceived crowding may occur when density levels are high. Bury has pointed out that management has the responsibility of protecting the 
ecological integrity of the resources from the people and for the people. Many people have moved to the Galápagos in search of new economic opportunities and management must protect the resources from the many tourists who visit and the residents who are trying to make a living, so that visitors and residents will be able to continue enjoying and using the resources well into the future. The needs of the residents, tourists, and the tourism industry, as well as the resources must be considered. The growing resident population has provided many more boats, currently there is a tremendous amount of excess physical capacity. This uncontrolled growth must be restricted before there will be any control over tourism at the visitor sites.

Washburne's (1982) interpretation of social carrying capacity fits in with the results from this study. He feels that monitoring the type and frequency of use is far more useful than calculating an actual capacity because amount of use is not always the relevant factor. Unacceptable conditions may be monitored and eliminated through methods other than reduction of use. Social impacts may occur at any use level, for example, if an acceptable range was established between five and ten groups at a visitor site at one time, negative social impacts could still occur even if there were only two groups present. If individuals from one group were chasing after sea lions to pet them, this activity may greatly reduce the satisfaction experienced by others. Controlling the use level in this case has no effect on social impacts, it is the type of activities. 
Managing the types of activities should take priority over controlling the number of groups.

Many factors complicate the methods of determining a relationship between social impacts and use levels such as the problems in getting accurate responses due to multiple expectations, discrepancies, social interference, and coping strategies. Recreational displacement also plays a role. Expectations dictate how a person will respond. People's responses to activities at a visitor site are guided by discrepancies between expectations and actual experiences. Every individual responds differently to the discrepancies and this has an impact on satisfaction levels. The way a person responds on a survey may not accurately reflect true feelings.

It is also difficult to get accurate measures of satisfaction because people use coping strategies to reduce the negative impacts. These strategies include modification of expectations to minimize discrepancies. Satisfaction, or social impacts may be rated high regardless of actual satisfaction in order to reduce internal conflict.

Perceived crowding is very difficult to measure. According to Ditton, Fedler, and Graefe (1983), crowding is more related to expectations, preferences, and previous experiences than perceived encounter levels. Expectations, preferences, and previous experiences are all different so there is no uniform way to measure crowding.

Recreational displacement is another example of why these surveys fail to obtain the desired result. over time, 
as the Galápagos have become increasingly popular, individuals who prefer areas of solitude may choose not to visit any more. The definition of the area changes and the people who prefer solitude are displaced by individuals who are more tolerant of larger numbers of people. The result is a relatively constant level of satisfaction despite increasing numbers.

In this study, each visitor site is a different size, with varying terrain, plants, and animals. Since respondents did not visit all the same sites, and average responses were used, details on the individual sites were lost.

\section{Recommendations}

In the Galápagos islands National Park, detailed information already exists regarding the individual sites. The length of trails, size of visitor areas, and time required to visit a site are all known. Individual sites can be monitored and evaluated based on visitor responses. Pattern and amount of use can be adjusted to address issues as they occur. The visitors should be asked:

Did you enjoy your visit at this site?

What did you expect at this site?

What did you see?

How many other groups did you see?

How many groups did you expect?

How many groups do you feel would be appropriate at this site at any one time? 
Was there something that your guide, or other visitors did that greatly added to your enjoyment?

Was there something that your guide, or other visitors did that reduced your enjoyment?

Please make any suggestions, complaints, or comments that would have improved your experience at this visitor site.

The earlier carrying capacity studies that provide maximum limits have not been enforced. This shows that calculation of a carrying capacity produces a number that is not enforceable. The values are not realistic in terms of actual use and demand. Many of the calculated capacities have been exceeded at individual visitor sites, and it is not known what the result is. Have the areas been destroyed because that magic number was surpassed?

Currently, the Park is opening up additional visitor sites to help reduce the pressure on the most heavily visited areas. There are proposals for placing all boats on fixed itineraries. This will be very difficult to achieve, but it allows the Park Service to enforce and monitor use more easily. As the system operates now, some boats are on a fixed itinerary, but others seek approval for their routes every day, or every few days, and it changes from week to week. Once itineraries are fixed, the same tour operators will encounter one another on a fixed schedule, and as a result, interactions among these groups can be monitored more easily.

The Galápagos Islands are a unique and beautiful place to visit and provide a source of income for Ecuador, but 
they must be utilized most carefully. Understanding the social carrying capacity is critical to the long term survival. This study helps tourism managers understand the problems with social carrying capacity studies, and how social carrying capacity and social impacts can be monitored and controlled in the Galápagos. 


\section{APPENDIX 1}

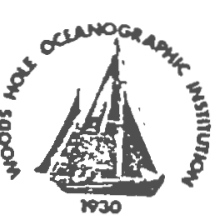

GALAPAGOS TOL'RISY

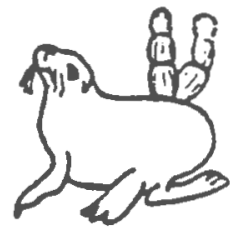

A Survey of Tourists About Their Sarisfaction and Concerns

Instruct lons

This study is betng condueted by the Loods Hole Oceanographie Institution, United Staces, with t:. support and eooperation of the Coverseent of Ecuador. Information from this study will be used:

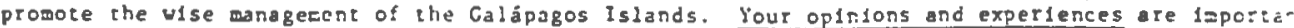
therefore, ve ask you to spend a few pinutes to assist us by ansuering this questionnaire.

Only the person or persons who pald for the vacation should fill out the questionnalre. Hotever, spouses, chiddren and guests are telcose to assist in filling it out.

PLEASE ALSHER ALL QLESTIONS THAT FERTALN TO YOU. Citting answers to sowe questions alght rECLEthe usefulness of other answers. Your ansters are anonyous, but please try to be accurate.

The questionnalre is divided into 4 sections for your convenience. You are invited co alie additional coments on the back pase.

Please return the completed questionnafre to your tour guide.

I. FIRST LEE ASK YOU FOR SOYE IMPCFTAIII BACKGROLTD ISTORYAIION.

1) What is today's datc? (Please urite your ansters in the spaces belou).

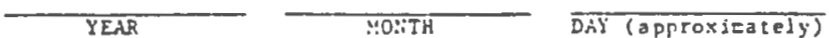

2) bhere do you live? (Please write your ansiers in the spaces beloti)

\section{COLATRI TIAIETFROIE:TE - CITITTOWX}

3) How wany days is your total vacation? (Plesse fricluce All desinations AiD travel tise)

4) How any days are you spending in the Galjizzos islands on your vacation?

$$
\text { Lits nit :HE Griprigos }
$$

5) hñat would you ta:e core if yeu did not tabe this vaction? (C1rcle the number rext to $\because a u$. anster. Please notice tiat icssithe ansiess appear in two colvons.)

1. WORKED

2. STAYED AT HO:E
3. I DO NOT KLIOH

4. GO:E ELSEATERE O:: vaCATIO: (pleuse sfecj: where: 
6) What wajor destifations ortec ilian the Galápagos are you visiting as pare c: zour vacation? For example, Quito or Machu Picchu?

OTHER MAJOR DESTINATIOI:S:

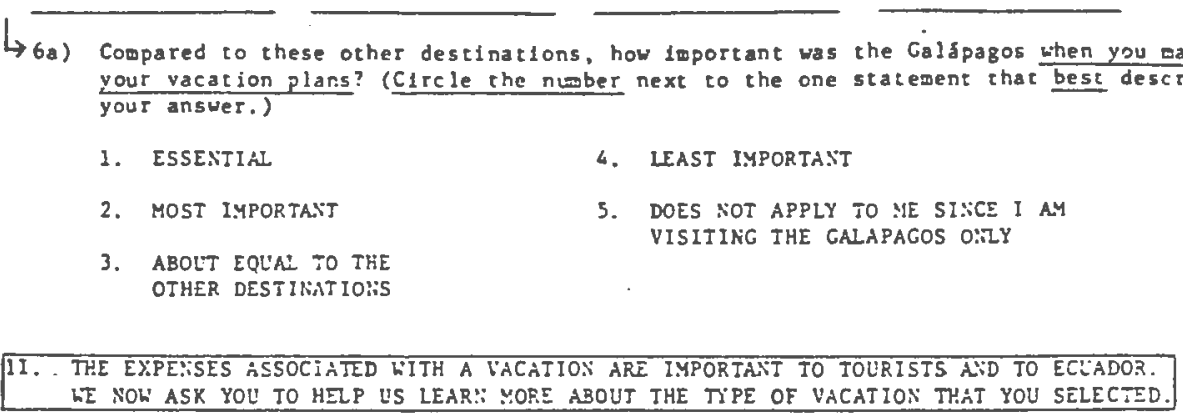

7) How vany people did you or your househald pay for on this vacation? please inelude yourse!f: PEOPLE INCLLDING MYSELF

8) that statement best describes your transportation to the Galipagos? (Circle the number)

1. FLICHTS TO QUITO, TO CLAYAQUIL, AND THEN TO THE GALAPAGOS

2. FLIGHTS TO QUITO AND TO GUAYAQUIL, AND THEN A CRUISE TO THE GALAPAGOS

3. FLIGHTS TO GLAYAQLIL AID THEN TO THE GALAPAGOS
4. FLICHT TO GLAYAQUIL AND THEN A CRLISE TO THE GALAPAGOS

5. OTHER (please specify:

9) What statezent( $s$ ) cescribes your vacation plass for the Galspagos? (Circle the nivber nex: : each stategent that applies to you)

1. ARRANCED AT A TENIEL AGE::CY BETORE ACTLALLY GOING ON VACATIO::

2. ARRA::GED AT A TRAVEL AGE:C: IX GUITO

3. ARRAYGED AT A TPAIEL ACE:CY I:: GLAMNIILIL
4. ARRASGED I: TAE GALAPAGOS

5. OTHER (please specify:

10) Which of the followis scricices are included as part of your Calápagos vacation packacc? E: "package" te tican a collecicich of servicestrat has a single price. (Circle the rugter nex: : each serviec that arplies to yeí)

1. I DID :OT BLYY A PACPMGE

2. FLIGHT TO QUITO A:D/OE GLiY:RQLIL

3. FLIGHT TO THE GALAPAGOS

4. CRUISE TO tHE GA APAGOS

5. MEALS
6. hCCO::10DATIONS

7. halNISG tOLRS IN THE Galapacos

8. SCUBA DIVIIT TOLRS IN THE GALAPAGOS

9. OTHER (please specify:

$$
\because
$$


11) Please ESTIuATE all expenses for transportation that are not included in your package. If all transportation is included ener zero. Include everycre you paid for. (Please specify eurrenc ABOLT (please specify currency)

22) What are your accomodations in the Calápagos? (Circle the number next to each accoumodation that applies to you)

1. HOTEL

2. SAILBOAT

3. SMALL BOAT (LESS THAN 25 PASSË:GERS)
4. LARCE BOAT OR SHIP (25 TO 100 PASSENCERS)

5. OTHER (please specify:

\section{I. THIS SECT1O: IS DETC.ED TO YOLR ENJOYYEYT OF YOLR VISIT TO THE CALAPACOS.}

13) The following types of wildlffe are representative of the Galapagos Islands. Did you see exasples of these wildife not in captivity on any of vour guided tours of the islands?

\section{CAREFLLLY CIRCLF THE APPROPRIATE SMIBOL FOR EACH TYPE OF WILDLIFE.}

TYPE

BOOBY

WALED ALBATROSE

FRIGATE BIRDS

FLICHTLESS

CORYORANTS

D.AR'IN FINCHES

PERCUIN

LICHTFOOT

SALLY CEAES

CIALIT TORIOISE

SEA LION

FUR SEAL

LA:D ICLANA

MARI:E ICLA:ia

OPL:IIA CACTLS

L

$\rightarrow 13 a$ )

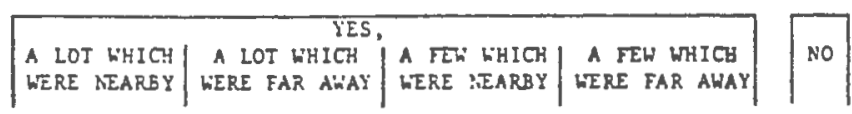

$\begin{array}{ll}\delta & z \\ \delta & z \\ 6 & z \\ \delta & z \\ \delta & z \\ \delta & z \\ \delta & z \\ \delta & z \\ \delta & z \\ \delta & z \\ \delta & z\end{array}$

2
$z$
$z$
$z$
$z$
$z$
7
2
2
$z$
$z$
$z$

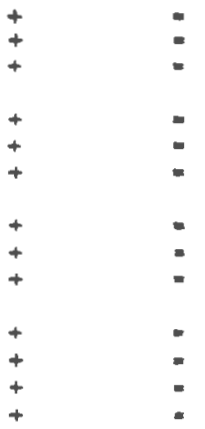
1. YES
2. $\therefore 0$

14) Please ESIIYHTE the nuter of sites that you visited on the Galapagos in guided tours? AROLI SITES

25) Please ESTIMATE the aycrage nu=ber of people that have been in your tour groups. AECI? PEOPL 1::CLLDI:T NSSEF

$415 a)$ bhich stategent best describes your satisfaction with the size of the groups.

I. THERE LERE FAR TCO :US'X PEOFLE IN THE CROLPS

2. THE GROLPS WERE A LITRE TDO B!C
3. THE SIZE OF THE TOUR GROLPS DID NOT BOTHER IE AT ALL

2. THE GROLPS LERE TOO SYALL 
16) Please EstIMAiE the average nubber of of he? groups thot you saw during a cypical cour onshore. ABOL'T QTHER GROLTS SER: ELRI:C A T:PICAL TOLR

(16a) what statedent best describes hct sceing the ocher groups affected you?

1. I DID NOT SEE ANY OTHER TOL'R GROLPS

2. SEEIN:G THE OTHER TOLR GROL'PS DHA VERY BOTHERSO:IE

3. SEEI:: THE OTHER TOL'R GROUPS WAS SO:ELLHAT BOTHERSOYE
4. SEEINC THE OTHER TOLR GROLPS DID SOT BOTHER VIE AT NLL

3. SEEIKC THE OTHER CROUPS ADDED TO $\mathbb{Y}$ ENJOYYENT

17) The rext questions are cesigned to "Eeasure" your satisfaction with the guided tours. Your answers should be basen an the ahove inforsation on tour groups and wildiffe.

$\rightarrow$ 17a) If you kneu in acvance what the tours bould have been like, would you stll have chesea is. come to the Galapagos?
1. YES
2. $: 0$

17b) In addition to the costs of travel, food and accossodations, you paid 56 t.s. or $\$ 30: \because .5$. for your visitor's card deperding on thester you live in Ecuador. Do you think that the visits which this cart ade possible were worth the additional cost for the card?
1. YES
2. $:: 0$

17c) Simlarly, what sere the visits wor:h to you? That is, what is the maximun fee that you would have been willing to pay for a visitor's card? Ask yourself what fee vould have been just high enough to aske you decide not to visit the Galapagos.

THE MAXIMLY FE THAT I WOLLD HAVE BEEN LILLING TO PAY IS (please specify eurrency)

IV. FINALIY, WE ASK YOU TO HELP LS LEAR: YOSE ABOLT YOLRSELF AND YOUR HOUSEYOLD. DECISIONS ABOUT VACATIONS ARE ISFLLE::CED STRO:GL: BY YOL'E AVAIIABLE TIME AND IXCONE, AND BY OTHER PERSONAL CHARACTERISTICS. THIS I:TCRNATIO:: IS :EEDED FOR STATISTICAI PLRPOSES O:IY IN ORDER TO ANALYZE THE RESFO:SSES WE CET FROY DIFFERENT PEOPLE, YOUR ANSWERS ARE STRICIL: ANONYMOLS. WVERTHELESS. PLEASE DE AS ACCLRATE AS POSSIBLE.

18) Please anster the follo-irs questicrs ccecersing ho: you sperd your ti=e.

$\longrightarrow 183$ ) Are you a student?
1. YES
2. $: 0$

I8b) Are you retired?
1. IES
2. $: 0$

18c) Do you have a $f u 1:-t i=e$ job?
$\sqrt{ }$ 1. YES
2. $\quad$ :io

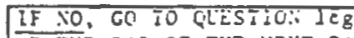
18d) II IES, please EST?:-1:E : he a:c:ase nuther of hours you work fer week.
ABOUT holas $r E:$ : $\because E::$

18e) IF IES, hoi ang vacaticn days to you get this year ineluding this vacation? TOTAL VACATIO: DAYS THIS YEAR

18f) IF YES, do you get paid for your vacation days?
1. YES
2. $: 10$
(CONTINUE AI QUESTIO:: 18E) 
$18 \mathrm{~g}$ ) Are you self-eeployed?
1. YES
2. $\$$

18h) Do you have a part-ti=e job?

प 1. YES

2. 10

IE :

181) If YES, PIease ESTIMATE the average number of hours you work per veek. ABOUT HOLRS PER LEEK AT A PART-TIME JOB

18j) IF YES, please ESTIMATE your hourly wage.

$\sqrt{2}$ ABOUT PER HOUR

19) The next two questions concern how you allocate your money to vacations.

$\longrightarrow$ 19a) Please ESTIYhIE what you expect the total cost will be for your entire vacarion by the tice it ends? Please inelude all people that you pald for.

ABOLT (please specify currency)

19b) Plesse ESTIMATE what you expect to spend for all vacations this vear. Including this ose ABOUT FOR ALL VACATIOSS THIS YEAR (please specify currency)

20) Savings and Incore deteralne what tourists can afford to spend on vacations. Although the sext questions are personal, the information is yerj 19pottant and we only esk for estiwates.

$\rightarrow 20 a$ ) Please ESTIMAIE what your household has in savings and Investoents. For convenience, the categorles are in L.S. dollars. For your information, \$IU.S. Is about equal to 1 co Ecuadorian cucres.
1. LESS IHAY \$5,000
5. $\$ 50,000$ To $\$ 99,999$
2. $\$ 5,000$ 70 $\$ 9,999$
6. $\$ 100,000$ TO $\$ 199,999$
3. $\$ 10,000$ 10 $\$ 24,999$
7. $\$ 200,000=\$ 299,999$
2. $\$ 25,000$ 工0 $\$ 49,999$
5. $\$ 500,000$ CR YORE

20b) Please ESTIUATE whot yeu expect your cotal household's annual facoce will be this :na:. (Please Include sages, dividends, Interest, and gifts.)
1. LESS IZ: $\$ 5,000$
4. $\$ 25,000$ TO $\$ 49,999$
2. $\$ 5,000$ To $\$ 9,959$
5. $\$ 30,000$ TO $\$ 99,990$
3. $\$ 10,000$ IO $\$ 2 \%, 090$
6. \$100,000 OR MORE

21) How old are you?
1. 20 TEASS OLD OR LESS
2. 21 TO 30 YEARS OLD
3. 31 TO 40 IEARS OLD
4. 41 TO 50 YEAES OLD

5. 51 TO 60 TEARS OLD

6. 61 TO TO YEARS OLD

7. 71 TO RO IEARS OLD

8. $\because$ OLDES TULA: 80 YEARS (PICASE ESTIMATE 
Fiere cigtit be other things that you would like to tell us.

Please use the space belor to rake addit lonal coments.

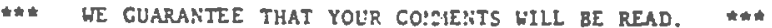

YOLR COHTRIELTIO:: TO THIS STLDY IS CEEATLY ATPAECIATED.

Marine Pollcy and Occan Sunagezent Center

hoods Hoie Decanographie Institution

hoods Hole, MA, USA 02543

(6.17) 54B-1600 Telex: 051679 


\section{APPENDIX 2}

\section{GALAPAGOS TOUAISM STUDY}

introduction

This survey is being conducted by the Coastal Resourses Management Program whi the suppuls t cou, oralion ef the Government of Ecuador. The objective is to gather intormation on the economic imponance of toutism to the Gulpergos which can be used so promole proper management, paticularly in ereas reserved lor human settements.

Please take a low minutes loward the end of yout visit to answer these questions. Aeturn the survey to your hotel manager or tourist guide.

It is preterible that the person paying for this vacation fill out the survey. All responses will remaln enonymouns.

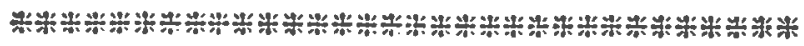

1 General Inlormation

1) Wheredoyume? hes Aace les CA CSA

2) How many lofal days is this vacation?

a) How many of these days are spert in trave!?

14 Lays

During your visin 10 the Galapagos, where and how long dis you stay?

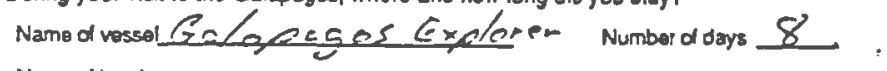

Name at hotel

Number of days -

4) What other siles will you visit in Ecuador as pan of this vacation and how bong will you spend in each?

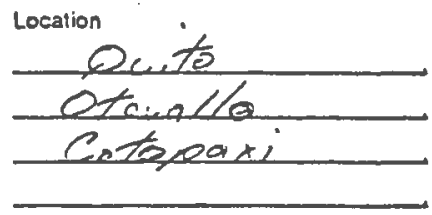

Number (or part) ol days

5) What other imponant locations, outside of Ecuador, will you visit during this vacation?

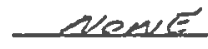

6) Rank the impontarts of the Galapagos, in relation to other sites visited, utilizing a numerical scale betwe on -2 (teast important) and +2 (most imponant). +2

7) II you could not have visited the Galapagos as pan of this vacation, what would you have done? weuld vot Have come this wacapem

8) Where did you artange your visit to the Galapagos?

Cin a travel agency outside Ecuador

In a travel ageney in mainland Ecuador.

In the Galápagos

Others (please specily)

9) What is your age?

10) How many hours do you normally work per week? $40-5^{-} \mathrm{O}$

\section{Expenses}

1) How many persons, including yoursetl, dis you pay lot to make this vacation? $2 \ldots$

2) Please estima your lamily income during 1990, o $25,000 U S \ldots ; \ldots$ 
3) Ploase estimate all the expenses per person associated with this vacation, epecitying the currency, next il. the services tisted bolow:

a) If your visit to the Galapagos was part of a lour package, write the tonor I (hacluded) naxt to sonvices

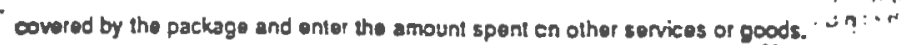

- Hyour vish is part of a tour package, how much did li cost per porson?

$\%, 20045$

b) Place an $X$ next to expenses that are not appicable to you.

Cosuperson Services/goods $\quad \therefore \cdots$ :

2 persen 6 nights $x 40 \frac{1}{29045}$ Rotels in mainland Ecuedor

Hossels in the Galapagos
Hotels in the Galapagos
Meals in the Galapagos
Oner day trips or excursions to the interior of the islands

Other expenses in the Galapagos (park entrance foe, lips, souvenirs, etc.)

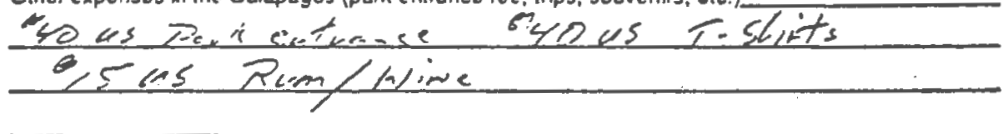

III Visitor solisfaction

1) On a scale of 1103 , three being the best, how would you rank:

2. SYour satisfaction with the nature you saw in the Galapagos.

2 . 5 Your satistaction with the services you received in the Galapagos.

2) What could have, been done to bener your visit to the Galapagos? pllews geportumitifs to sit ancl cuatch the animils fer a whils, patier. the a aleeys curlling

3) II you have visit the Galapagos betore, how many times? Lupaliz

4) Do you expect to visit the Galapajos again? ? 2 in inf a l/ke to

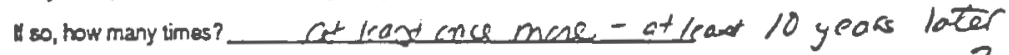

5) Please estimate the average member of groups that you saw on a typical trip to a visitor site. 2

a) Which phrase best describes how seeing these other goups aflected you?

_ I saw no other groups.

_ Seeing other groups bothered mo greally.

$\checkmark$ Seeing other groups bothered me a lititi

_Leeing other groups did no: bother me.

_ Seaing other groups added to my erjoyment.

6) On a scale of 1 10 3, three being the best, indizate the importance of the sines you visited on the following map. 


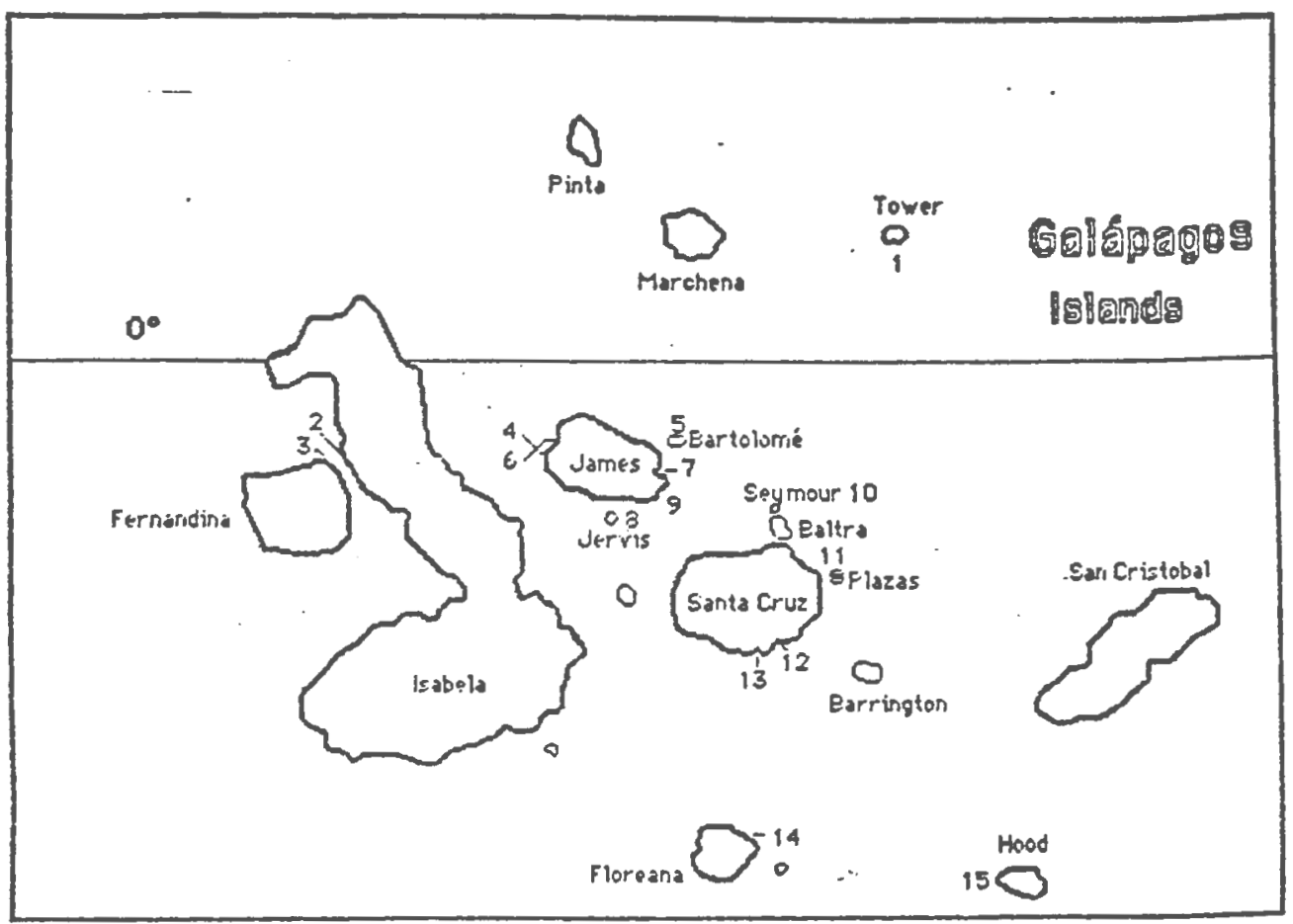

PRIHCIFAL YISITOR SITES

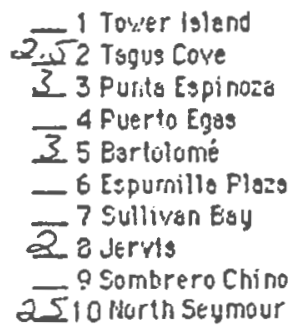

211 South Plozo

112 Puerto Ayoro

1 13"Turtle" Bay

214 Punta Cormorant

315 Punte Suárez

$\frac{1}{2}$ otros oche pars

2510 Narth Seymour

-

COMMENTS: 
APPENDIX 3

Calculation of WTP and Number of groups, controlling for income.

$r$ wto groups . income

$$
\begin{aligned}
& =-.16-(.212)(-.04) \\
& \sqrt{1-(.212) * \sqrt{1}-(-.04)} \\
& =-.15
\end{aligned}
$$

$$
F=\frac{.0225}{.9775} \text { (217) }
$$

$$
=4.99
$$

90 


\section{BIBLIOGRAPHY}

Agardy, Tundi, Bruce Epler, Lynne Hale, and Stephen olsen. Draft Profile of the Galapagos Province of Ecuador. Coastal Resources Center. University of Rhode Island, 1986.

Aguas, Milton. Candidate for Governor, Galápagos Islands, Interview by author, March 4, 1992.

Barry, Tom, Beth Wood, and Deb Preusch. The other side of Paradise: Foreign Control in the caribbean. New York: Grove Press, Inc., 1984 .

Becker, R. H., Alan Jubenville, and G. W. Burnett. "Fact and Judgement in the search for a social Carrying Capacity." Ieisure Sciences 6 (1984): 475-486.

Blalock, Hubert M. Social statistics, 2nd. ed. New York: McGraw Hill, 1979.

Boo, Elizabeth. Ecotourism: The Potential and Pitfalls. Vol. 1. Washington, D.C.: World Wildlife Fund, 1990a.

Boo, Elizabeth. Ecotourism: The Potential and Pitfalls. Vol. 2. Washington, D.C.: World Wildlife Fund, 1990b.

Borgatta, Edgar F. "MY student, the Purist: A Lament". Sociological Quarterly 9 (1968):29-34.

Bosselman, F. In the wake of the Tourist. Washington, D.C.: Conservation Foundation, 1978.

Boyce, Barry. A Traveler's Guide to the Galapagos Islands. San Jose, CA: Galapagos Travel, 1990.

Broadus, J., I. Pires, A. Gaines, C. Bailey, R. Knecht, and B. Cicin-Sain. Coastal and Marine Resources Management for the Galapagos Islands. Marine Policy and Ocean Management Center. Woods Hole Oceanographic Institution, 1984 .

Broadus, James M., and A.G. Gaines. "Coastal and Marine Area Management in the Galapagos Islands." Coastal Management 15 (1987): 75-88.

Broadus, James M. "The Galapagos Marine Resources Reserve and Tourism Development." Oceanus 30 (1987): 9-15.

Brower, Kenneth, ed. Galapagos: The Flow of Wildness, Volume 1, Discovery. NY: Sierra Club \& Ballantine Books, 1970 .

Brower, Kenneth, and Eliot Porter, eds. Galapagos: The Flow of Wildness, Volume 2, Prospect. NY: Sierra Club \& 
Ballantine Books, 1970.

Burch, william R. Jr. "Much Ado about Nothing-some Reflections on the wider and Wilder Implications of social Carrying capacity." Leisure sciences 6 (1984): 487-496.

Bury, Richard L. "Recreation Carrying Capacity-Hypothesis or Reality?" Parks and Recreation 11 (1976): 22-25, 56-57.

Cifuentes, Miguel. Plan de Manejo y Desarrollo. II Fase. Parque Nacional Galápagos. Comision de Alto Nivel Plan Maestro Galápagos. Quito, Ecuador, 1984.

Colgan, Mitchell W., and David I Malmquist. "A Dry Trek Through a Galapagos Coral Reef." Oceanus 30 (1987): 61-66.

Cribb, James. Subtidal Galapagos. Camden East, Ontario: Camden House Publishing Ltd, 1986.

de Groot, R.S. "Tourism and Conservation in the Galapagos." Biological Conservation 26 (1983): 291-300.

deKadt, Emanuel, ed. Tourism: Passport to Development? New York: Oxford University Press, 1979.

Desor, J.A. "Toward A Psychological Theory of Crowding." Journal of Personality and Social Psychology 21 (1972): 79-83.

Ditton, Robert B., Anthony J. Fedler, and Alan R. Graefe. "Factors Contributing to Perceptions of Recreational crowding." Leisure sciences 5 (1983): 273-288.

Ditton, Robert B., and Marc L. Miller. "Coastal Recreation: An Emerging Area of Managerial Concern and Research Opportunity." Leisure Sciences 8 (1986): 223-239.

Edwards, steven F. "The Demand for Galapagos Vacations: Estimation and Application to wilderness Preservation." Coastal Management 19 (1991): 155-169.

Emory, Jerry. "Tourism and Tension in Galápagos." The World and I (February 1989): 648-657.

Epler, Bruce c. Initial Profile of Resource Management Issues to be Considered Through the ZEM Planning Process in Galapagos. International Coastal Resources Management Project. The University of Rhode Island, 1990.

Epler, Bruce c. "Whalers, Whales, and Tortoises." Oceanus $30(1987): 86-92$. 
Farrell, Bryan H. "Cooperative Tourism and the Coastal Zone." Coastal Zone Management Journal 14 (1986): $113-130$.

Febres-Cordero Ribadeneyra, Leon. "The Galapagos Marine Resources Reserve Decree." Oceanus 30(1987): 4-5.

Fisher, Anthony C., and John V. Krutilla. "Determination of optimal Capacity of Resource-Based Recreation Facilities." Natural Resources Journal 12 (1972): 417444 .

Graefe, Alan R., Jerry J Vaske, and Fred R. Kuss. "Social Carrying Capacity: An Integration and Synthesis of Twenty Years of Research." Leisure Sciences 6 (1984a): 395-431.

Graefe, Alan R., Jerry J Vaske, and Fred R. Kuss. "Resolved Issues and Remaining Questions about social Carrying Capacity." Leisure Sciences 6 (1984b) : 497-507.

Gramann, James H. "Toward a Behavioral Theory of Crowding in Outdoor Recreation: An Evaluation and Synthesis of Research". Leisure Sciences 5 (1982): 109-126.

Greist, David A. "The Carrying Capacity of Public Wild Land Recreation Areas: Evaluation of Alternative Measures." Journal of Leisure Research 8 (1976): 123-128.

Greist, David A. "A Reply to Heberlein and Shelby." Journal of Leisure Research 9 (1977): 149-150.

Gunn, C. A. Tourism Planning. New York: Crane Russak, 1979 .

Haulot, Arthur. "The Environment and the Social Value of Tourism." International Journal of Environmental Studies 25 (1985): 219-223.

Heberlein, Thomas A., and Bo Shelby. "Carrying Capacity, Values, and the Satisfaction Model: A Reply to Greist." Journal of Leisure Research 9 (1977): 142-148.

Inskeep, Edward. Tourism Planning: An Integrated and Sustainable Development Approach. New York: Van Nostrand Reinhold, 1991.

Instituto Nacional Galapagos. (INGALA). Indicadores Regionales. Unidad de Planificacion, 1987.

Jackson, M.H. Galapagos: A Natural History Guide. Calgary, Alberta, Canada: University of Calgary Press, 1985.

Kasteleijn, Henk w. "Marine Biological Research in the Galapagos: Past, Present, and Future." Oceanus 30 
Kenchington, Richard A. "Planning for the Galapagos Marine Resources Reserve." Ocean \& Shoreline Management 12 (1989): 47-59.

Kenchington, Richard A. "Tourism and Conservation in the Galapagos Islands, the Great Barrier Reef and the Republic of Maldives." CAMP Network Newsletter 13 (September, 1990): 1-2.

Kenchington, Richard A., and M.T. Agardy. "Achieving Marine Conservation Through Biosphere Reserve Planning and Management." Environmental Conservation, 17 (1990): 3944 .

Kraus, Richard., and Lawrence Allen. Research and Evaluation in Recreation, Parks and Leisure studies. Columbus, Ohio: Publishing Horizons, 1987.

Laarman, Jan G., and Richard R. Perdue. "Science Tourism in Costa Rica." Annals of Tourism Research 16 (1989): 205-215.

Labovitz, Sanford. "Some Observations on Measurement and Statistics." Social Forces 46 (1967):151-160.

Lea, John. Tourism and Development in the Third World. London: Routledge, 1988.

Lindberg, Kreg. Policies for Maximizing Nature Tourism's Ecological and Economic Benefits. Washington, DC: World Resources Institute, 1991.

Liu, Juanita C., and Pauline J.Sheldon. "Resident Perception of the Environmental Impacts of Tourism." Annals of Tourism Research 14 (1987): 17-37.

MacDonald, I.A.W. "Some Ideas on Visitor Utilization of the Islands in the Galápagos National Park." FitzPatrick Institute, University of Cape Town, Republic of South Africa, April, 1987.

Machlis, Gary E., Diana A. Costa, and Jose Cardenas Salazar. Galapagos Islands Visitor Study. Moscow, Idaho: University of Idaho, 1990.

Manning, Robert E., and Charles P. Ciali. "Recreation Density and User Satisfaction: A Further Exploration of the Satisfaction Model." Journal of Leisure Research 12 (1980): 329-345.

Mathieson, A., and G. Wall. Tourism: Economic, Physical, and Social Impacts. New York: Longman, 1982. 
Merlen, Godfrey. "Diving in the Galapagos." Oceanus 30 (1987): 20-26.

McFarland, Craig. President, Charles Darwin Foundation, Telephone Interview by author, January 17, 1992.

Miller, Marc L., and Robert B. Ditton. "Travel, Tourism, and Marine Affairs." Coastal Zone Management Journal 14 (1986): 1-19.

National Park Service, Galápagos Islands, Ecuador. Papers, "Number of Tourists Visiting Selected sites within the Galápagos National Park during 1989", 1991.

Perez Camacho, Efrain. "Two Legal opinions - on the Ecuadorian Law." Oceanus 30 (1987): 16,18.

Ramakrishna, Kilaparti. "Galapagos Marine Reserve International Issues." Oceanus 30 (1987): 17,19.

Robinson, Gary R. "Negative Effects of the 1982-83 El Nino on Galapagos Marine Life." Oceanus 30 (1987): 42-48.

Romeril, Michael. "Tourism and the Environment - Towards a Symbiotic Relationship." International Journal of Environmental Studies 25 (1985): 215-218.

Salm, Rodney Victor. "Integrating Marine Conservation and Tourism." International Journal of Environmental studies 25 (1985): 229-238.

Schreyer, Richard. "Social Dimensions of Carrying Capacity: An Overview." Leisure Sciences 6 (1984): 387-393.

Sevilla, Roque. "A Promise to the Sea, and the Politics of the Decree." Oceanus 30 (1987): 6-8.

Shelby, Bo. "Research, Politics, and Resource Management Decisions: A Case Study of River Research in Grand Canyon." Leisure Sciences 4 (1981): 281-296.

Shelby, Bo, and Rick Colvin. "Encounter Measures in Carrying Capacity Research: Actual, Reported, and Diary Contacts." Journal of Leisure Research 14 (1982): 350360 .

Shelby, Bo, and Thomas A. Heberlein. "A Conceptual Framework for Carrying Capacity Determination." Leisure Sciences 6 (1984): 433-451.

Shelby, Bo, and Thomas A. Heberlein. Carrying Capacity in Recreation Settings. Corvallis, Oregon: Oregon state University Press, 1986.

siegel, Sidney. Nonparametric Statistics For the Behavioral 
Sciences, 2nd ed. New York: McGraw Hill, 1988.

Singh, Tej Vir, H. Leo Theuns, and Frank M. Go, ed. Towards Appropriate Tourism: The Case of Developing Countries. Frankfurt, Germany: Peter Lang, 1989.

Smith, Valene L., ed. Hosts and Guests: The Anthropology of Tourism. Philadelphia: University of Pennsylvania Press, 1989.

Sorenson, Jens. "The Lure of Ecotourism and Carrying Capacity." CAMP Network Newsletter 13 (September, 1990): 6 .

Sorensen, Jens C., and Scott T. Mccreary. Coasts: Institutional Arrangements for Managing Coastal Resources and Environments. National Park Service, U.S. Department of the Interior, Washington, D.C., 1990 .

Stankey, George H., and stephen F. McCool. "Carrying Capacity in Recreational Settings: Evolution, Appraisal, and Application." Leisure Sciences 6 $(1984): 453-473$.

Towle, Edward L. The Island Microcosm. Washington, D.C: Island Resources Foundation, 1984.

United Nations. Transnational Corporations in International Tourism. New York: United Nations, 1982.

Vaske, Jerry J., Maureen P. Donnelly, and Thomas A. Heberlein. "Perceptions of Crowding and Resource Quality by Early and More Recent Visitors." Leisure Sciences 3 (1980): 367-381.

Villa, Jose L., and Arturo Ponce. "Islands for People and Evolution: The Galapagos." National Parks Conservation \& Development. 1986.

Warner, Edward. "Can Binoculars, Cameras and Daypacks be the Rainforest's New Hope?" Environmental Action (Sept/Oct 1989): 18-21.

Washburne, Randel F. "Wilderness Recreational Carrying Capacity: Are Numbers Necessary?" Journal of Forestry $80(1982): 726-728$.

Wilkinson, Paul F. "Tourism and National Parks in Island Microstates: Caribbean Case studies." in proceedings of the Congress on Coastal and Marine Tourism, EastWest Center, Honolulu, Hawaii, May 1990.

wilkinson, Paul F. "Conservation, Tourism and National Parks in the Eastern Caribbean." CAMP Network 
Newsletter 13 (September, 1990): 3-4.

Young, George. Tourism Blessing or Blight? Middlesex, England: Penguin Books, 1973. 